\title{
QUADRANGLE COURTYARD GREEN SIMULATION APPROACH TO RENOVATION OF RESIDENTIAL BUILDINGS IN CHINA
}

\author{
BY \\ JIAQI LIU \\ A thesis \\ submitted to the Victoria University of Wellington \\ in fulfillment of the requirements for the degree of \\ Master of Interior
}

Victoria University of Wellington

(2021) 


\title{
Table of Contents
}

\author{
Abstract \\ 1.Introduction
}

1.1Introduction 1

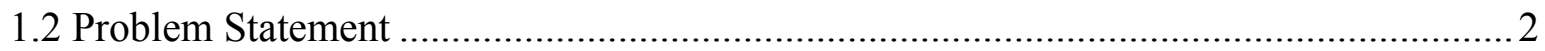

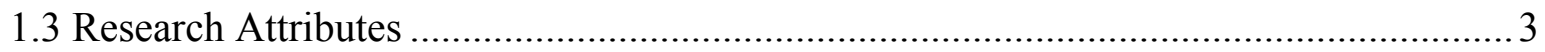

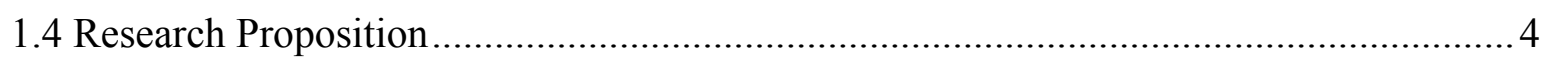

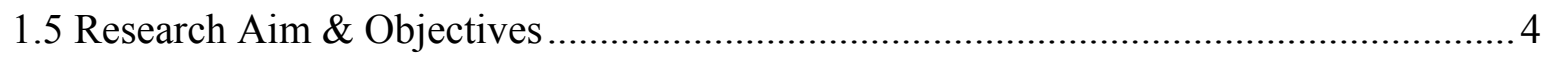

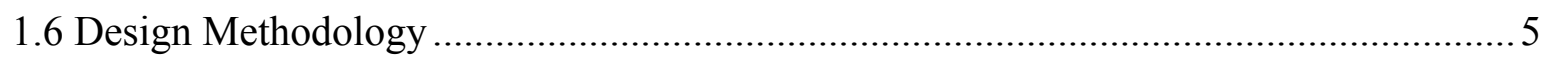

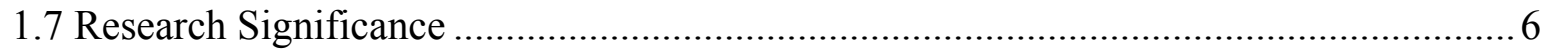

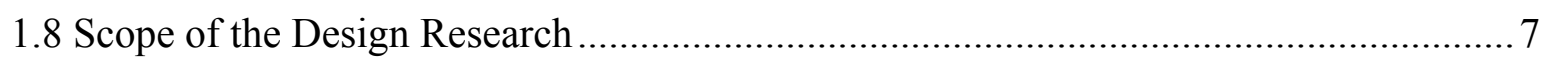

2. Literature Review

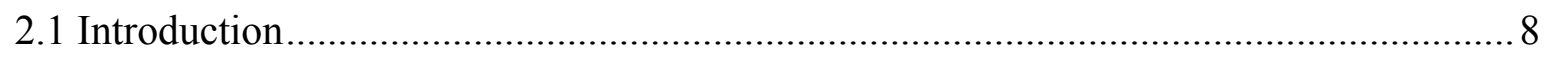

2.2 History of Chinese Courtyard (Siheyuan).......................................................... 15

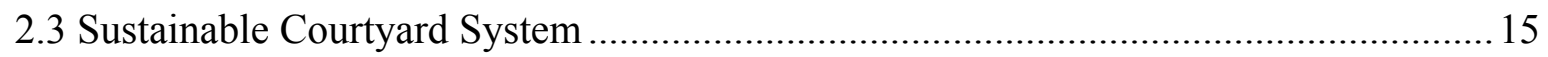

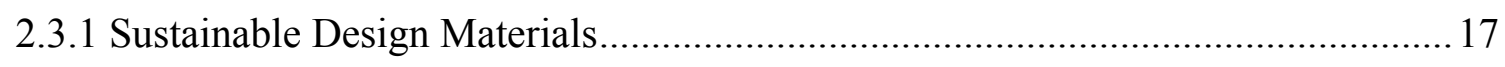

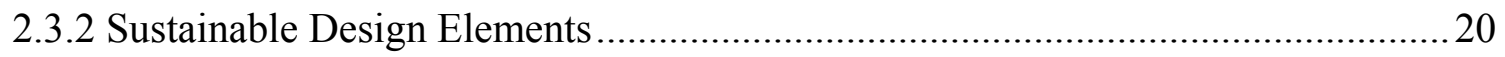

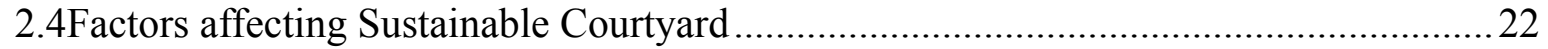

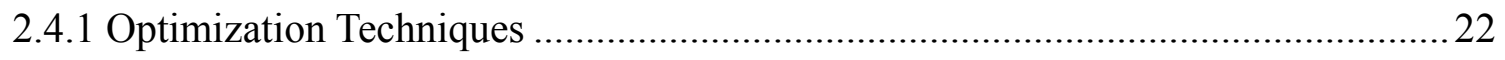

2.4.1.1 Design Considerations for Optimization ...................................................23

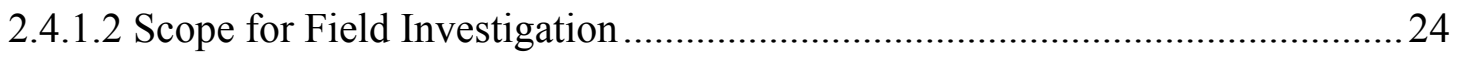

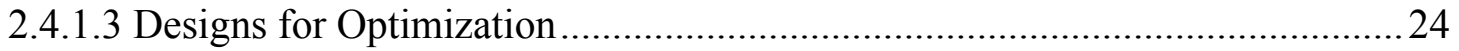

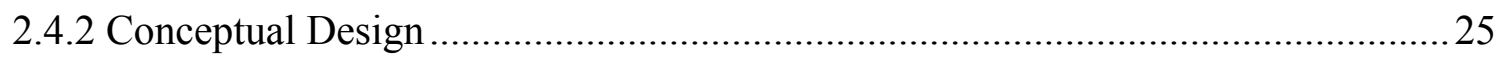




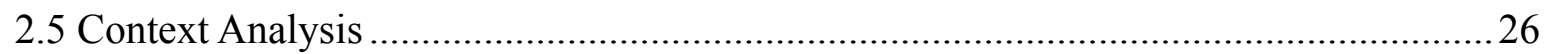

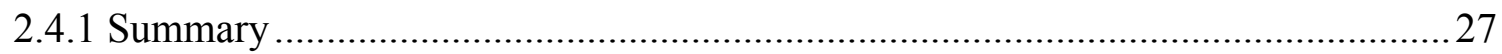

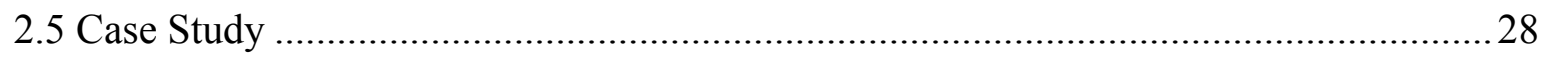

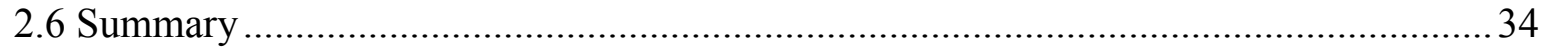

3. Site Analysis

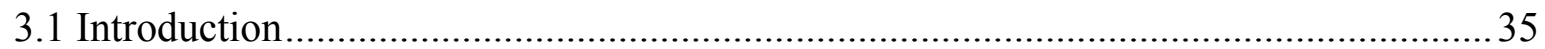

3.2Study Area

3.3 Current Situation of Beijing Courtyards (Siheyuan) ............................................... 36

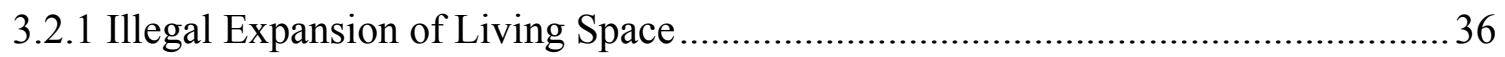

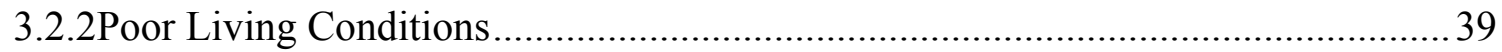

3.4Current Situation of Courtyard Houses in Cha'er Hutong............................................ 40

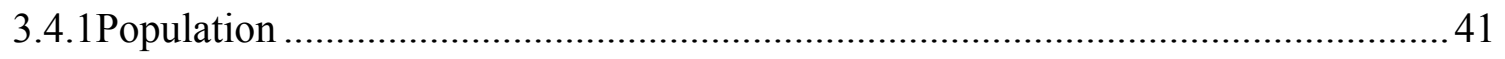

3.4.2 Retention of Traditional Courtyard Houses ....................................................... 41

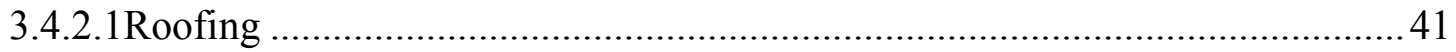

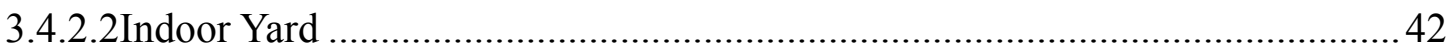

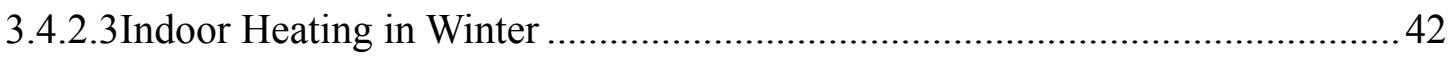

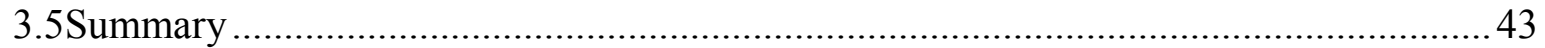

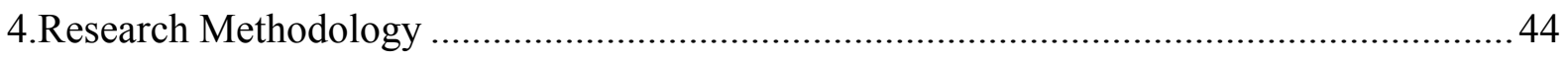

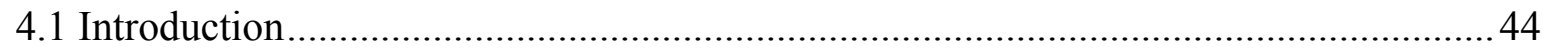

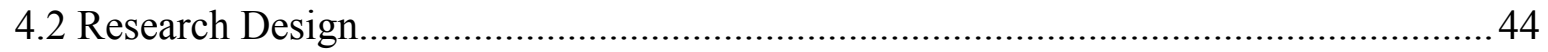

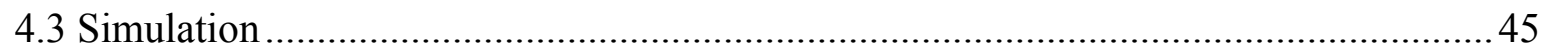

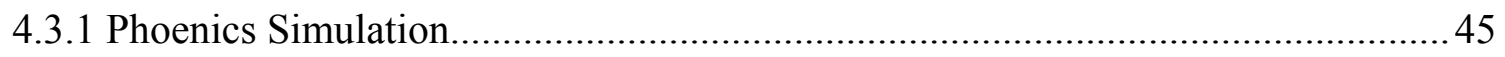

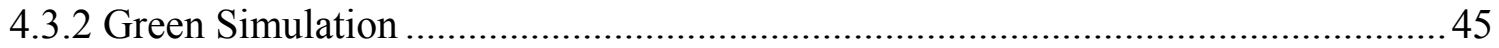

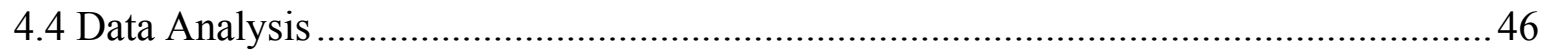

5.Results\& Discussion 
5.1 Introduction

5.1.1 Wind Simulation Results

5.1.2 Green Simulation Results

5.1.2.1 Energy Result

5.2.1.2 HVAC Result

5.2.1.3 Ventilation Results

5.2 Design Solution

6.Conclusion \& Recommendations

6.1 Introduction

6.2 Research Revisit

6.2.1 Research Objective 1

6.2.2 Research Objective 2

6.2.3 Research Objective 3

6.3 Implication of Research

6.4 Limitations

6.5 Closing Remark 


\section{Abstract}

Development of technology and the rapid increase in population has led to tremendous growth in the population of China. Beijing the capital city has become significantly overcrowded due to a high number of residents. The traditional courtyard houses have been drastically transformed and lost their cultural values over time. The quadrangle courtyard reflects the work and art of conventional Chinese residences. An average Beijing quadrangle courtyard building reflects both utility and aesthetics in its design and development. Quadrangle courtyard is designed to have a family-centered pattern with neighbors of the trunk and the community area for social networking and finally denotes cultural profundity. The poor architectural designs and ineffective construction practices have caused many problems in the city regarding sustainability and environmental protection, which has, in turn, increased the concerns of people towards building the traditional houses to ensure better living standards and greater sustainability. This study aims to conduct an evaluation of applications of green construction practices of the traditional courtyard houses on the renovation and reconstruction of contemporary residential buildings in Beijing.

The study utilizes quantitative approaches for collection and subsequent evaluation of data regarding the subject matter of the research. With respect to the literature review, thesis has performed a review of different literature including journal articles, books, newspapers, and other publications, while for collection of primary data has used with computer-assisted architectural simulation models, which is then analyzed through data triangulation technique. Further, a base model and reference models are generated for computer simulation usingPhoniecs and Green Simulation Studio software's, for the analysis and to analyse the influence of internal courtyard and courtyard for wind flow. The model that exhibits the best width to length ratio and natural room environment is chosen for evaluation. The study was conducted in the residential areas of Dashilar Hutong, Jingyang, Deyang,Dongcheng District, Yue Hutong, Changchun Street Hutong Area, and Yongning District. The study is limited to the 
given areas only, and no evaluation is performed on other areas of the city and buildings that are not recently renovated or reconstructed. The study also provides recommendations to the architect firms and regulatory authorities regarding applications of green construction practices of the traditional courtyard houses on the renovation and reconstruction of contemporary residential buildings in Beijing. In the assessment, the spatial design of courtyards is balanced; the aspect ratio is planned to crate natural buffer space is created.

Further, to examine the performance of the courtyard design the study applied the Computational Fluid Dynamics (C.F.D.) programming, Parabolic Hyperbolic, or Elliptic Numerical Integration Code Series (PHOENICS), for wind condition simulation. Later with the help of the Green build studio of Autodesk, the study had undergone Green Simulation. The Quadrangle courtyard building performance is analyzed by Green BuildingStudio to generate outputs like heating and cooling loads, and monthly electricity and fuel consumption, and their life cycle cost. Results show for a courtyard with a decent combination of courtyard layout and aspect ratiois chosen. Finally, the study suggests the best suited planning strategy for the new proposals and design implications for a new courtyard from the angle of green building construction.

Key Words: Traditional Courtyards, Quadrangle Courtyard Green Simulation (QCGS), Sustainable Development, Green Construction, Renewal, Building Renovation, reconstruction, Beijing. 


\section{Introduction}

\subsection{Introduction}

The basic need for people lives is shelter. In China, the technological advancements and development of society had increased the rise of demand for improved living standards in housing. The expanding population and international exposure and boost of economy had raised the residential building as apartment types. Wu (1997) stated that majority of designs for the new buildings in china are been influenced by the western and Singapore styles. However, the value of these courtyard houses cannot be denied, also the most of the residents are presume modern living can only achieve with current living. But the essence of traditional courtyard building can also be utilized for modern days to draw the benefits of environment (Heath \& Tang, 2010). Further, Chinese architects are exploring the uniqueness of traditional architectural form. For instance, figure 1 shows the Beijing Courtyard house Ju'er Hutong is identified to be the first of its kind for renewal of traditional Beijing courtyard building adopted a novel approach for renovation by Liangyong in 1991.

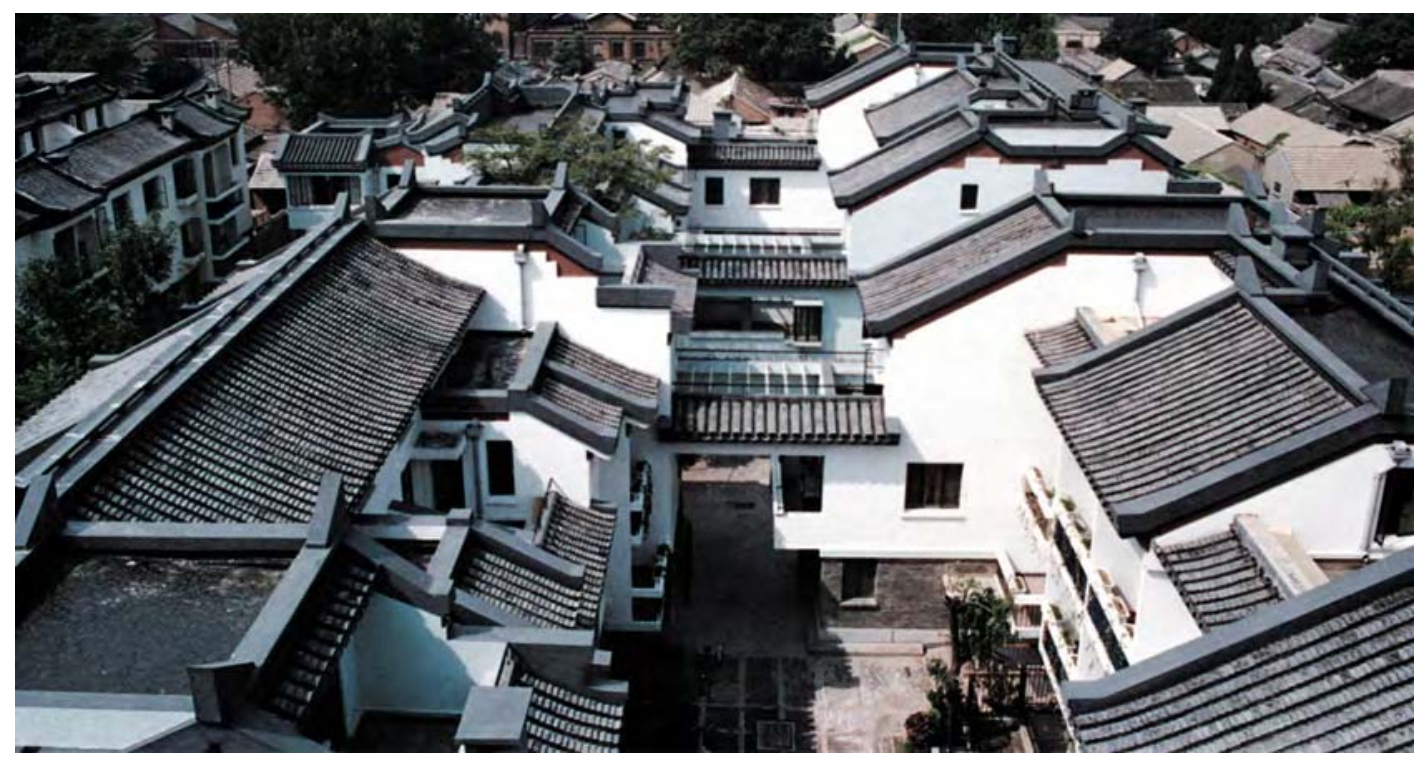

Figure 1. View of Ju'er Hutong Courtyard housing- Renewal project Source: http://www.arch.tsinghua.edu.cn/IAUS/index.htm 


\subsection{Problem Statement}

With the development of technology, scope for need of large building spaces to meet the urban growth Chinese cities. The demolition of traditional courtyard houses began from the early 1950 s to the late 1980 s. The traditional courtyards, where only one family used to live were reconstructed with certain expansion in its area and the number of buildings to accommodate more families and individuals, as a result by the end of 1977, a typical courtyard house in Beijing witnessed accommodating more than 8 households at a time (Yang). The overcrowding of traditional courtyard houses has drastically transformed its structure and historical purpose because from 1985 to 1999, it could be seen that the majority of such courtyard houses even didn't have a courtyard in it (Sungho Lee, 1999). The lives of people living in these buildings become highly miserable because the sustainable architectural standards were significantly ignored in designing and constructing these structures. The ineffective approaches of modern architectural activities cause wastage of resources and construction pollution in the region, which negatively affected the lives of inhabitants in that area.

It is also provided that the reconstruction of these traditional courtyards were carried out without considering the height to distance ratio of these buildings with the other buildings in the neighborhood, which in turn affected the amount of sunlight, ventilation of fresh air and caused several problems with respect to the effective management of water and moisture in the structures (Zhang, 2006). In the past two decades, a number of attempts have been made to address the problems caused by the integration of modern architecture into the reconstruction and renewal of the traditional courtyard houses in Beijing and also to sustain the traditional culture of Chinese architecture. For example, two new courtyard housing projects were initiated in the inner Beijing: the Jouer Hutong prototype in the Nanlougu Xiang area and the 
Nanchizi experiment in the eastern Forbidden City (Zhang, 2006).

However, these initiatives mainly focused upon the preservation of the historical values of architectural culture, societal impacts of such houses on the inhabitants, and inheritance of the traditional architectural culture among modern architectural practices. None of the initiatives addressed the structural problems associated with the reconstruction or adaptation of the traditional courtyard houses, for example, their struggle for sunshine, heat, summer ventilation, drainage, material saving, and green construction practices for responding effectively to the Beijing's low winter temperature and spring climatic conditions. These issues have demanded considerable attention to conduct a further investigation for incorporating green construction practices of the traditional quadrangle courtyard in the renovation of contemporary residential buildings in Beijing.

\subsection{Research Attributes}

\subsubsection{Research Question}

In order to investigate the application of green building experiences of traditional courtyard houses on the renovation of contemporary residential buildings in Beijing, the main research question is developed as under:

-What are the applications of Quadrangle Courtyard Green Simulation(QCGS) on the renovation of contemporary residential buildings in Beijing? 


\subsection{Research Proposition}

To effectively answer the main research question of the study, the following sub-questions are developed.

-What was the green building practices involved in the construction of traditional courtyard houses in Beijing?

-What are the applications of Quadrangle Courtyard Green Simulation(QCGS) on the renovation of contemporary residential buildings in Beijing?

-What will be the optimum building design to address the sustainable development issues in the renovation and reconstruction of contemporary residential buildings in Beijing?

\subsection{Research Aim \& Objectives}

The study aims to evaluate the possible applications of Quadrangle Courtyard Green Simulation(QCGS) on the renovation of contemporary residential buildings in Beijing. It is evaluated that the increasing development in technology and rapid urbanization of the Chinese cities, especially Beijing has caused a number of issues regarding the sustainability of contemporary buildings, which in turn negatively affected the living standards and lifestyle of its residents.

In order to accomplish the given aim of the study and find appropriate answers to the given research questions and evaluate the validity of the hypotheses developed by the 
researchers, the following main objectives of the study have been identified.

-To investigate the implications of construction and architectural practices adopted in the past on the development and building of traditional courtyard houses in Beijing.

- To examine the impact of Quadrangle Courtyard Green Simulation(QCGS) on residential buildings in Beijing.

- To develop sustainable design strategies for reconstruction and renovation of the contemporary residential buildings in Beijing.

\subsection{Design Methodology}

In order to evaluate the construction practices and architectural approaches adopted in the construction of traditional courtyard houses in the past and their corresponding implications on the green building initiatives and environmental sustainability, the study will make critical analysis and review of the past literature including journal articles, newspapers, books, and other publications. The study can identify and access the relevant literature by performing comprehensive research through different keywords related to the given subject matter on different platforms over the internet, including academic libraries, Google books, online journal articles, and news websites. The validity of a secondary resource can be conducted on the basis of the evaluation of the authors or underlying sources of the data by gathering information regarding the qualification of the authors and relevance of the source with the building and architectural industry.

With respect to finding the underlying implications of green construction practices in 
the achievement of sustainability in the construction of traditional courtyard houses in Beijing, the study collected primary data from the participants through pre-structured questionnaires and surveys mechanism. Similarly, the study also collected primary data regarding the prevailing sustainability in the contemporary buildings of Beijing and the traditional courtyard houses located in the city through computer-based architectural simulation through Phoenics, DeST (designer's simulation toolkit) HVAC software that includes taking photographs, making drawings and collecting data on the scale of 1:500 with an objective of examining the shadow movement inside the courtyard during different times in a day and different times of the year. The data collected through architectural simulation to drive a conclusion on the field research. The triangulation of primary data will also help in suggesting an optimum design strategy for reconstruction and renovation of the contemporary residential buildings in Beijing.

\subsection{Research Significance}

This study is of high significance for the architectural firms and the government policymakers because it would provide a detailed insight on the possible solution of one of the major prevailing problems of sustainable housing in the overcrowded city of Beijing. It will help in formulating an optimum strategy for building the contemporary houses in Beijing with effective sunshine ratio and other sustainable advantages, including material saving, reduction in construction pollution, attainment of climate-friendly green construction methodologies, better summer ventilation, and drainage facilities. The findings will help the policy makers and urban planners to develop certain sustainable polices that can assure a sustainable and healthy living environment for the urban population. It will also considerably add to the existing literature on the topic of green construction and urban planning from both the future 
research perspectives and architecture teaching in universities. The future researchers can use it as a foundation for conducting further evaluation on green construction and modern building and architecture practices, while the architecture teaching can use this study as a string reference in delivering their academic courses and curriculum on architecture. Moreover, the limitations identified in this study regarding the inefficiencies of computer-based simulations would help the software developers to conduct further evaluation on the identified limitation and come up with more sophisticated software solutions to address the prevailing inefficiencies in an effective manner.

\subsection{Scope of the Design Research}

The scope of this study is to conduct an evaluation of the green construction practices adopted by the architects in the construction of the traditional courtyard houses in Beijing and how these practices can be applied to developing sustainability in the contemporary buildings and house structures of Beijing. The study will conduct an evaluation of the residential areas of Dashilar Hutong, Jingyang, Deyang,Dongcheng District, Yue Hutong, Changchun Street Hutong Area, and Yongning District. It will focus only on the evaluation of courtyard houses and the modern buildings that have been developed on the concept of courtyard houses or recently renovated or reconstructed. All the other building structures and streets that are not mentioned above shall be excluded from the scope of this study. 


\section{Literature Review}

\subsection{Introduction}

Chapter 1 discuss the drop-down of traditional Chinese houses to create accommodation for number of families at a place. In the process of creating accommodation, there is a drastic loss in the thermal comfort of the building. Ignoring standards at the time of designing and construction causes miserable living conditions This chapter discusses the history of the Chinese court, the creation of a sustainable courtyard based on materials and elements, and factors affecting courtyards.

Courtyard buildings are utilized today around the globe, taking advantage of nearby atmosphere attributes. They remain a traditional building segment in Asia, the Middle East, South America, and Mediterranean nations (Al Masri et at., 2012). Jang and Ham led a study of courtyard type apartment blocks in South Korea, inspecting the layout, access, and a number of the courtyard story(Jang et al.,2017). considered the courtyard incorporated biological framework in China and its significant financial, ecological advantages(Han et al., 2016).Suneexplored the traditional courtyard space and considered the effects of standard components, for example, light, water, and soil, on the conventional dwellings for courtyard houses(sun et al., 1981). The geographical position of Beijing located in the northeast of China has the diversity in the climate with four seasons of continental monsoon, widespread winds during summer coming from southeast and northwest in the winter. It is affected by the strong Mongolian high pressure in winter, forming the world's coldest region at the same latitude. While in summer, it is affected by the North Pacific subtropical high, forming a typical continental monsoon climate (Hu, 2012). In other words, Beijing is in the transition zone between dry and cold airflow and warm and humid airflow. According to the Beijing Statistical Yearbook (2019), the average annual 
sunshine duration in Beijing from 2007 to 2016 is 2421.1 hours and the average daily sunshine time in Beijing is 6.6 hours. This means that Beijing can be exposed to sunlight $63 \%$ of daytime during the years, so it is concluded at the end of paragraph that the sunshine conditions in Beijing are good. Beijing has four seasons each year, with winter from December to February and summer from June to August. The average annual temperature between the year of 2007 to 2016 is $13.5^{\circ} \mathrm{C}$. Beijing's coldest month occurs in January, accompanied by wind, rain, and snow. The average temperature in the month is $-3.1^{\circ}$ Cover an average temperature of $-0.9^{\circ} \mathrm{C}$ in winter. In contrast, summer temperatures are relatively comfortable, at $26.4^{\circ} \mathrm{C}$. The hottest month in summer is in July when the average temperature is only slightly higher than the summer's average temperature, maintained at about $27.4^{\circ} \mathrm{C}$. The below Table 2 shows the average temperature in Beijingfrom 2007-2016.

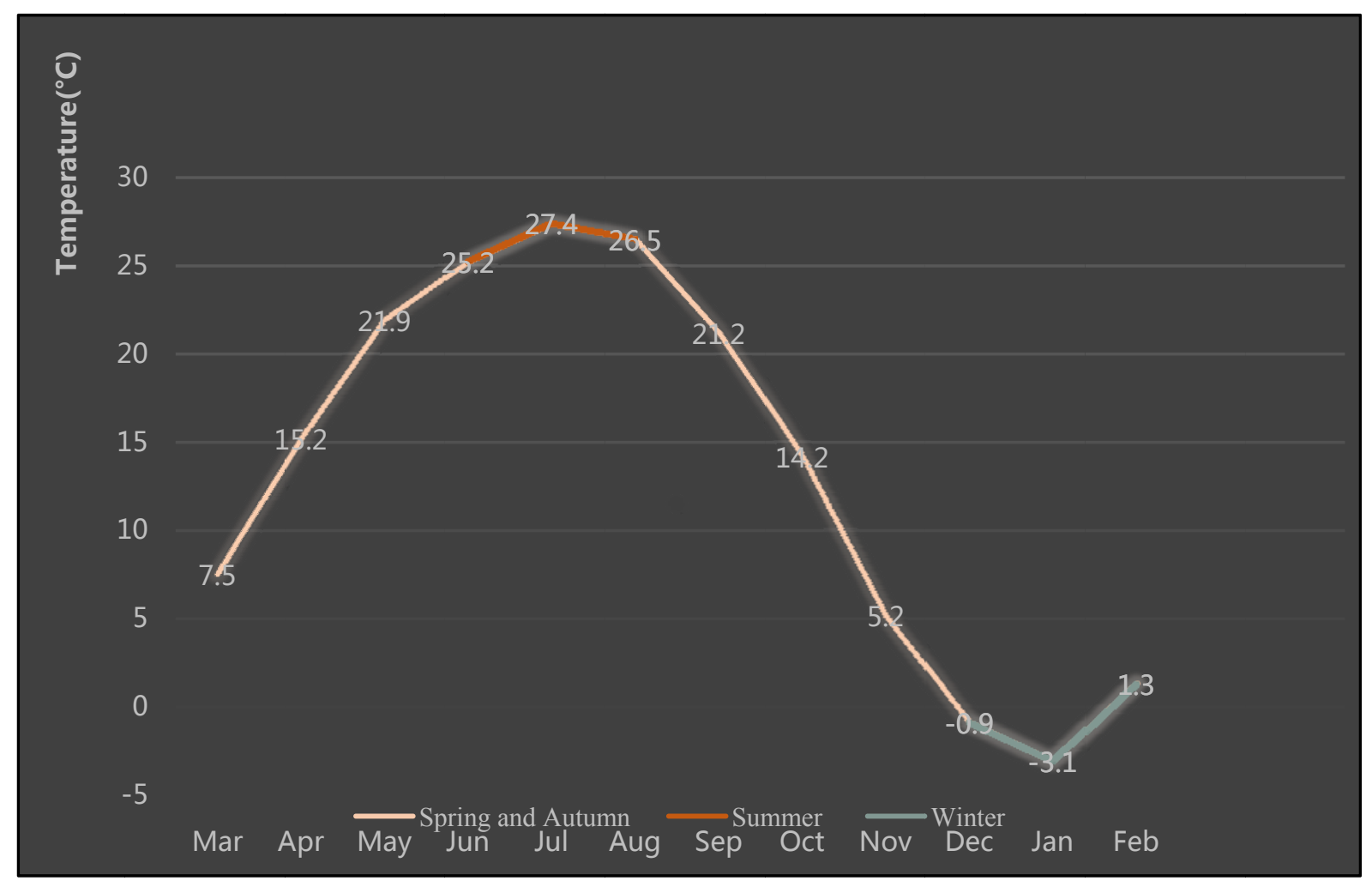

Table 1. Beijing Average Temperature from 2007-2016 (Beijing Statistical Yearbook (2019)) 
Since $2007-2016$, the average daily temperature below $5^{\circ} \mathrm{C}$ has 125 days, while the average daily temperature above $25^{\circ} \mathrm{C}$ has $20-80$ days. Therefore, Beijing is classified as belongs to Zone I.I.A. The Zone I.I.A. is one of the building climates zones that defined buildings in this area should meet the design construction requirements of heat insulation, cold and frost protection in winter, and heat protection in summer.

The average wind speed in Beijing from 2007 to 2016 is about $2.2 \mathrm{~m} / \mathrm{s}$. Spring and winter have the greatest impact of wind environment on human comfort due to the average wind speed and maximum wind speed are the highest among four seasons. Beijing's spring is from March to May each year, with an average wind speed of $2.7 \mathrm{~m} / \mathrm{s}$ and an average maximum wind speed of $8 \mathrm{~m} / \mathrm{s}$. The average wind speed in Beijing in winter is $2.2 \mathrm{~m} / \mathrm{s}$, and the average maximum wind speed is $7.7 \mathrm{~m} / \mathrm{s} . \mathrm{Lynch}$ proposed the influence of different wind speeds on people in Site Planning (Lynch, 2012). Book: Wind effects on structures: An Introduction to wind Engineering (Simiu\&Scalan, 1986) also addresses different wind speeds and different responses to comfort. Besides, Simiu and Scalan (1986) defined a wind speed of $5 \mathrm{~m} / \mathrm{s}$ as thelimit at which people can perceive comfort. As because the average wind speed in Beijing is always higher than $5 \mathrm{~m} / \mathrm{s}$, so that the wind environment in Beijing cannot be able to provide residents with a comfortable living environment, especially in winter. In other words, one of the most important design requirements for buildings in Beijing is wind protection in winter. 


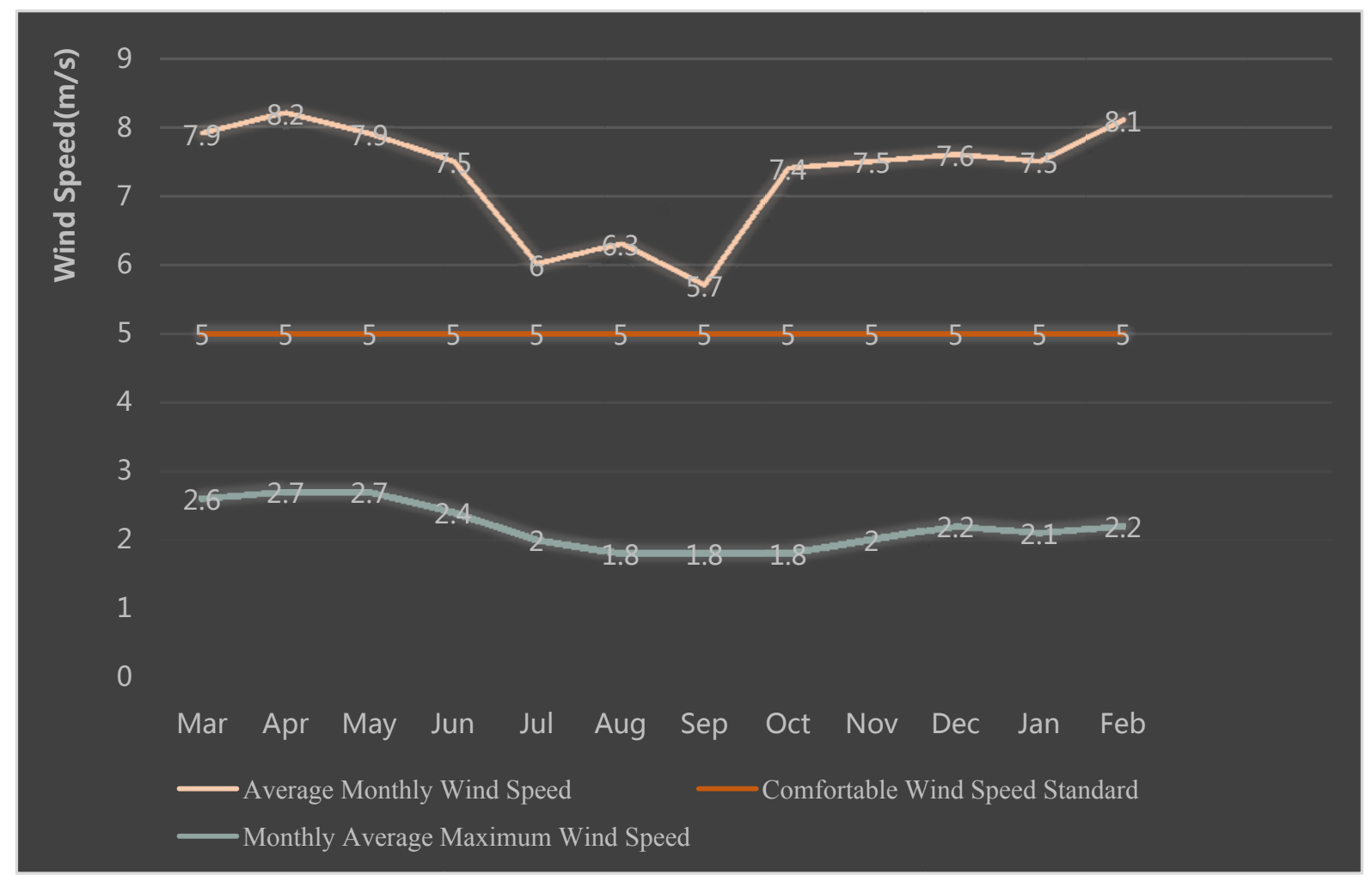

Table 2. Beijing Average Wind Speed and Maximum Wind Speed from 2007-2016 (Beijing Statistical Yearbook (2019))

Table 3. Wind Influences (Lynch, 2012)

\begin{tabular}{|c|c|}
\hline Wind Speed(m/s) & Effect on Human \\
\hline 2 & Light breeze \\
\hline 4 & Blows up the newspaper, messes up hair \\
\hline $\mathbf{6}$ & Start to feel out of control on walking \\
\hline $\mathbf{8}$ & Swinging clothes, move slowly \\
\hline $\mathbf{1 0}$ & Difficult to hold an umbrella \\
\hline $\mathbf{1 2}$ & Unsteady walking, harsh Wind \\
\hline $\mathbf{1 4}$ & Difficult to maintain balance \\
\hline
\end{tabular}


Table 4. Relationship between Wind Speed and Comfort (Simiu\&Scalan, 1986)

\begin{tabular}{|c|c|}
\hline Wind Speed(m/s) & Human Feeling \\
\hline $\mathbf{v}<\mathbf{5}$ & Comfortable \\
\hline $\mathbf{5}<\mathbf{v}<\mathbf{1 0}$ & Discomfort, action affected \\
\hline $\mathbf{1 0}<\mathbf{v}<\mathbf{1 5}$ & Very uncomfortable, the action is seriously affected \\
\hline $\mathbf{1 5}<\mathbf{v}<\mathbf{2 0}$ & Insufferable \\
\hline $\mathbf{v}>\mathbf{2 0}$ & Danger \\
\hline
\end{tabular}

An enormous portion of warm, humid territories is situated in the equatorial belt, belong to developing countries, which obstruct huge investments on advanced technologies to assess ventilation in courtyard buildings. To bringing down expenses, Computational Fluid Dynamics (C.F.D) projects may offer a significant worth for nearby architects to create a good design to maintain normal ventilation in the building. The qualitative information portrayed from the output is already of great importance for architects, even though the architect can easily locate the errors in the produced results because they are aware of the limitations of the local region. It permits simple control for the manipulation of the required parameters and analyzes the wind flow of the models (Leonardo Bittencourt et al., 2001).

D'Agostino and Congedo (2014) researched the adequacy of normal ventilation in a historical building situated in the South of Italy. The point was to discover a methodology that could be capable of providing an appropriate microclimate for the preservation in that building. Numerous studies around the globe have given some strategies to improve the thermal performance inside courtyard houses utilizing C.F.D. software. To refer to some of them, Chiang and Anh (2012) has considered the impact of characteristic improved ventilation inside courtyard houses in high-rise 
residential buildings utilizing a C.F.D. software called PHOENICS/FLAIR. The age of air and wind stream speed in the courtyard houses is watched for all circumstances. Taleghani et al. conducted another study on the normal ventilation inside the courtyard and another urban model., (2014). The courtyard building is analyzed for the hottest day so far in the atmosphere of the Netherlands (June $19^{\text {th, }}$ 2000 , with the greatest $33 \mathrm{C}^{\circ}$ air temperature). The outcomes set up that duration of direct sun and mean radiant temperature (M.R.T.) play a huge impact in thermal comfort. The courtyard (in contrast with different cases) offers the most comfortable microclimate contrasted with the other studied urban models.

Green building (G.B.) is otherwise called green construction development or sustainable building, which refers to building models in intelligent electrical, electronic and electromechanical devices are being used. These smart equipment sense and control the residents' activities and overabundant energy use just as monitor the building.(Costa et al., 2015). After 1990, PC-based simulation programming applications quickly created to the point that a graphical U.I. could fundamentally help in recreations and was faster than different techniques (Haves et al.,2011). The benefit of G.B. over traditional buildings is additionally critical; an exploratory report delivered by the U.S. general administration organization in 2009 discovered 12 economically planned buildings cost less to work and had fantastic green energy performance. For G.B., close integration of building systems, with an exceptional focus on energy sparing, is one of the necessary measures.

In this manner, utilizing modelling measures displaying the model, analysis of materials used, material investigation, and successful cooperation make a significant contribution to the design of high-performance Green Building. Thus, performance green buildings can be accomplished, which will decrease energy utilization and 
improve people's health, their ways of life, and their comfort (Korkmaz et al., 2010). With the advancement of software programs like DOE-2 and EnergyPlus, it is never been simpler for Building Groups to assess potential vitality sparing measures for a structured venture. Notwithstanding, getting ready information that precisely speaks to the proposed building and its energy efficiency features is an expensive, labor-intensive process. Accordingly, energy analysis is frequently delayed to a later point in the design process, which can restrict cost-effective options for boosting energy efficiency. With Green Structure Studio, modelers and architects can utilize their current P.C. helped plan frameworks to convey a task's structure math to the G.B.S. site, which leads an energy analysis of the building design. The program empowers the design team to look at the energy impact of early design decisions, compare alternatives, and share information more broadly with other team members. Utilizing 3-D computer-aided design (CAD) software from quite a few vendors, including Autodesk Revit, Bentley, and Graphisoft, architects develop their initial building configuration model, and afterward use gbXML and some basic inputs to export a building energy model.

Beijing's climatic characteristics make buildings mainly need to deal with the windproof and thermal temperature during winter to meet the standard of indoor living comfort of residents. Therefore, the study on traditional courtyard architecture will focus on the outdoor wind environment in the courtyard garden of Beijing Siheyuan and the thermal performance of the individual courtyard houses. In this study, the program is do wind analysis with Phoenics software and Green simulation with Green build studio. 


\subsection{History of Chinese Courtyard (Siheyuan)}

In China, courtyards are often called as Siheyuan. They are in existence from 2000 years before the Western Zhou period in China. There are a lot of changes that occurred in the courtyards to eradicate the problems created by the modern housing system in china. It is a typical house used as housing complexes, accommodating multiple families and also for providing extra spaces for free movement of air. Due to rapid economic growth in Beijing, demolition of old buildings was done. In this scenario, many courtyards are replaced by apartment blocks to accommodate overcrowding. Based on the data provided by the Beijing municipal administration of cultural heritage, there are over 500 historic siheyuan's are preserved for cultural representation. Recently, the latest version of Siheyuan is developed as a villa product on a large scale. They are commonly seen in new housing development scheme areas at Beijing(Zhang, 2014).

\subsection{Sustainable Courtyard System}

The theories and conspiracies developed in connection with "fullness" \& five "xu" by Emperor Canon they have categorized the courtyard deficiencies as inferior and fullness for becoming rich. The target phrases like size and space issues of the houses, wrong placement of stove and wall, few rooms with large courtyards \& big plots, homes with small entrance gate, drain water flow from south to east, and stocking of livestock at tiny houses. Finally, the theories formulated by "Emperor" Canon are treated as guiding principles to match the size of the home and household (Kou, 2005; Ma, 1999).

The original designs of the courtyard houses are planned to have a natural 
environment contributing to the wellbeings, good health, and enjoyable life for the occupants.

The most typical courtyard houses are so designed to with following specific architectural, structural characteristics to get benefit from enough sunlight, natural ventilation withstand the calamities like floods, an easy drain of water, conservation of natural habitats and environments combines the healthy and wealthy living of the occupants. Figure 2 shows the most typical courtyard house model in Beijing.

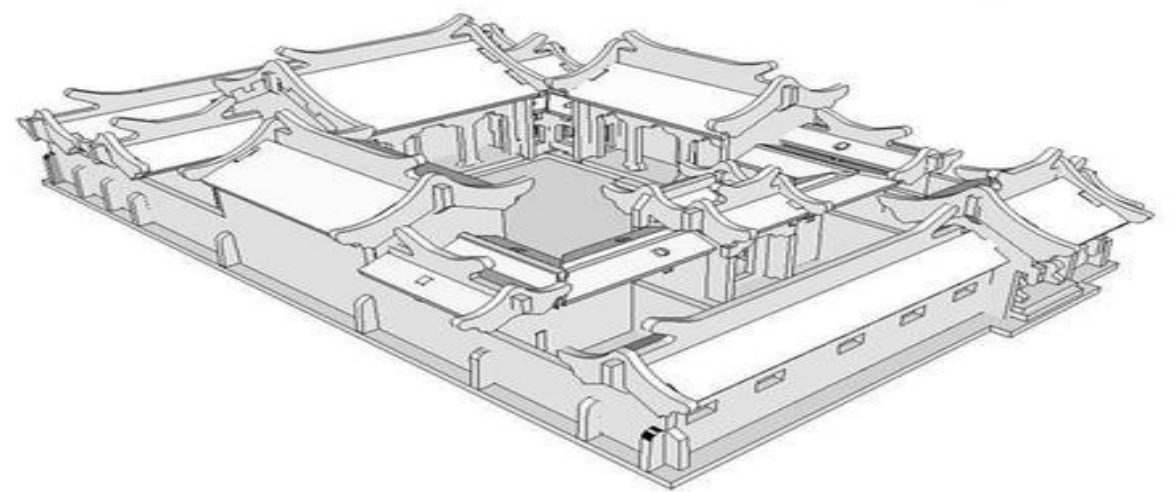

Figure 2. Typical Courtyard House Model of Beijing (computer model) (Zhang, 2014) 


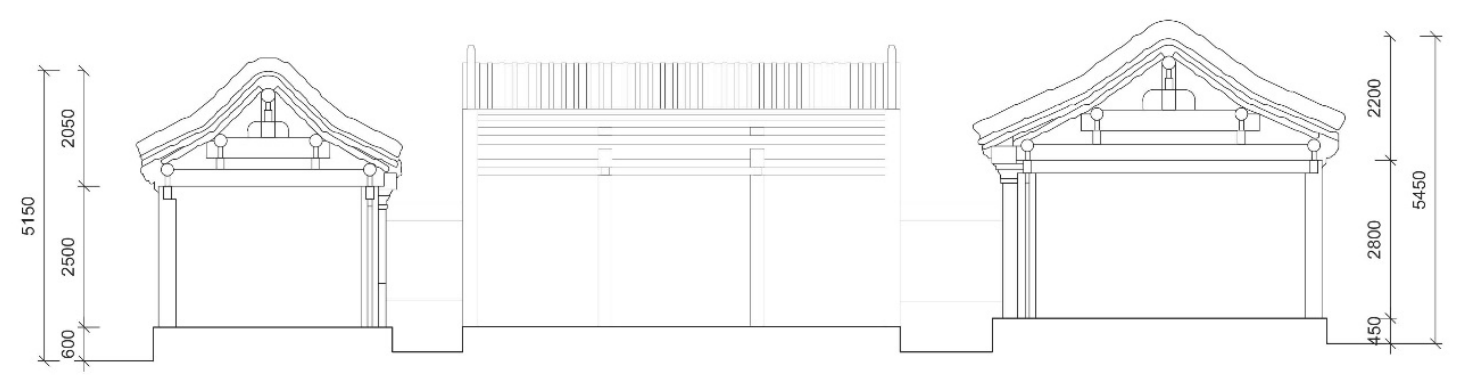

Figure 3. Section of Typical Courtyard House Model of Beijing (Drawn by myself) (Zhang, 2014)

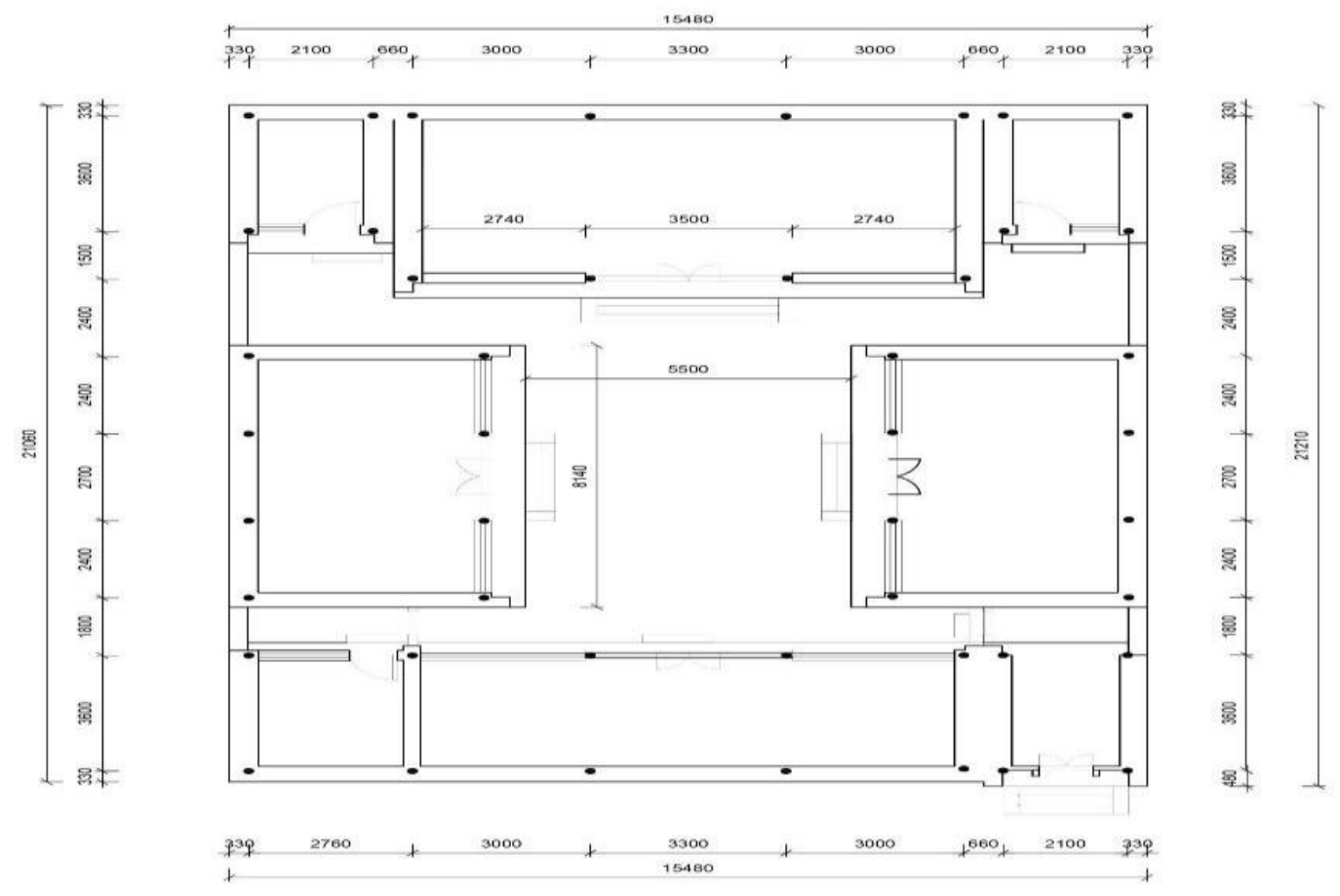

Figure 4. Plan of Typical Courtyard House Model of Beijing (Drawn by myself) (Zhang, 2014) 


\subsubsection{Sustainable Design Material}

The common type of materials used in Chinese traditional courtyard houses consisting of clay, wood, bamboo, corn, or cotton stalks. Where the wood is used at identified locations and clay bricks are used in the walls and structure. Plaster is also employed to protect clay, or clay brick walls from the rain, and also radiates the sun's heat away from a building. For roofs, depending on the wealthiness of a family, the material could vary, however clay is a fairly common material for making tiles of roofing. (Farzaneh,2016).

The building industry uses great quantities of raw materials that also involve high energy consumption. Choosing materials with high content in embodied energy entails an initial high level of energy consumption in the building production stage but also determines future energy consumption in order to fulfill heating, ventilation and air conditioning demands. (Zabalza, 2010). 
Table 5. Materials used to build Courtyard Houses

\begin{tabular}{|c|c|c|c|c|c|c|}
\hline Building Material & Density $\left(\mathrm{kg} / \mathrm{m}^{3}\right)$ & $\begin{array}{c}\text { Thermal } \\
\text { Conductivity (W/ } \\
\text { mK) }\end{array}$ & $\begin{array}{l}\text { Specific Heat (J/ } \\
\qquad \mathrm{kg} \mathrm{K)}\end{array}$ & $\begin{array}{c}\text { Primary Energy } \\
\text { Demand } \\
\text { (MJ-Eq/kg) }\end{array}$ & $\begin{array}{c}\text { Global Warming } \\
\text { Potential (kg } \\
\text { CO2-Eq/kg) }\end{array}$ & $\begin{array}{c}\text { Water Demand (1/ } \\
\text { kg) }\end{array}$ \\
\hline Reinforcing Steel & 7900 & 50 & 490 & 24.34 & 1.53 & 26.15 \\
\hline Aluminum & 2700 & 239 & 921 & 136.8 & 8.57 & 214.34 \\
\hline Flat Glass & 2500 & 0.95 & 837 & 15.51 & 1.14 & 16.54 \\
\hline Sawn Timber & 600 & 0.13 & 2385 & 21.0 & 0.3 & 5.12 \\
\hline $\begin{array}{c}\text { Glued Laminated } \\
\text { Timber }\end{array}$ & 600 & 0.13 & 2385 & 27.31 & 0.54 & 8.37 \\
\hline Cement & 3150 & 1.4 & 1550 & 4.24 & 0.82 & 3.94 \\
\hline Cement Mortar & 1525 & 0.7 & 780 & 2.17 & 0.24 & 3.33 \\
\hline $\begin{array}{c}\text { Reinforced } \\
\text { Concrete }\end{array}$ & 2546 & 2.3 & 1050 & 1.80 & 0.18 & 2.77 \\
\hline Concrete & 2380 & 1.65 & 1050 & 1.11 & 0.14 & 2.05 \\
\hline Clay Brick & 1800 & 0.95 & 1050 & 3.56 & 0.27 & 1.89 \\
\hline Sand-Lime Brick & 1020 & 0.29 & 908 & 6.27 & 0.00 & 1.42 \\
\hline
\end{tabular}




\subsubsection{Sustainable Design Elements}

According to the investigations on cultural, sustainable development in courtyard houses of Beijing, Zhang (2006, 2011 \& 2013) found that the Chinese philosophy, which was evident in classic buildings were replicated in the new siheyuan buildings. She proposes philosophical principles and the new angle for understanding the historical courtyard buildings. Zhang (2013) also explored the architectural designs contemplated with designing Siheyuan with features like windows, exterior walls, gates and access, windows, courtyards and gardens, roofs, interior space, floor levels, construction technologies, and building materials. The below Table 6 provides the characteristics of the Siheyuan.

Table 6. Characteristics of Siheyuan

\begin{tabular}{|c|c|}
\hline Characteristics & Beijing Siheyuan \\
\hline Exterior Formations & $\begin{array}{c}\text { With north- south axis 1-5 courtyards, } \\
\text { complex with 15-25 m wide and } 25-50 \mathrm{~m} \\
\text { deep. }\end{array}$ \\
\hline a. Walls & Red or grey bricks \\
\hline b. Entrance and gate access & S-E \& N-W corner \\
\hline c. Windows provision & $\begin{array}{c}\text { Green/red frames facing south as first } \\
\text { reference and also facing other directions }\end{array}$ \\
\hline d. Courtyards and gardens & $40 \%$ (7-20m) of ground area \\
\hline Roofs & $\begin{array}{c}\text { Pitched roof with grey tiles having slope of } \\
45^{0} \text { to } 60^{0} \text { also sometimes flat roofs. }\end{array}$ \\
\hline a. Floor levels & Mostly one Story \\
\hline b. Furniture styles & Beijing and stone table and stools in garden \\
\hline
\end{tabular}




\begin{tabular}{|c|c|}
\hline & and courtyard \\
\hline c. Facilities & $\begin{array}{r}\text { Water supply from well in hutong, kitchen in } \\
\text { the east side, restrooms in S-W or N-E } \\
\text { corner and heating the surroundings by } \\
\text { coal-burning. }\end{array}$ \\
\hline Building Materials & $\begin{array}{c}\text { Columns ad beams with wooden structures, } \\
\text { stone platform }\end{array}$ \\
\hline Construction Technology & Interlocking, timber joinery system. \\
\hline
\end{tabular}

The significant elements that are considered being the sustainable elements of the Beijing Siheyuan courtyards are due to the availability of features like natural amenities and the views of nature (mountains, valleys, and vegetation) also space for family activities. Concern with the features like the hierarchical organization of spaces is another good aspect during ancient days. With the writings of several various authors, it is evident that most of the structural parts of the courtyard buildings are constructed with woods, which is not considered as a sustainable activity of demolishing many numbers of trees, for now, days. Perhaps the Quality of construction resembles outstanding and long-lasting if proper maintenance was taken for the structure. For the modern time, the designers and architects need to learn and adopt the quality and excellence for modern construction. With artistic designs and the integration of buildings with greenery, Siheyuan represents the significant works of cultural and sustainable development deserver's attention. Perhaps some facilities are not ample and sophisticated. But modern designs and new developments should address previous problems. 


\subsection{Factors affecting Sustainable Courtyard}

\subsubsection{Optimization Techniques}

The traditional architectural designs clubbed with construction strategies are applied to fulfill the comfort and needs of the inmates, and well-structured surroundings with open spaces, are usually called as a courtyard. Predominantly in China, courtyards are the symbol of culture and the living style of the present Chinese civilization. The principles are still in use and consider the guidelines for designers and architects. Those buildings remain a traditional endeavor for most of the Mediterranean countries and continents like Asia, South America, and the Middle East (Al-Masri, 2012; Khan, 2008; Soflaei et al., 2016; Berardi, 2014). A study conducted by Jang \& ham (2017) in South Korea had reviewed the components of courtyard type apartments. Han et al (2002). observed the courtyard ecological system in the construction of buildings and the environmental benefits associated. In the province of Fujian and Zhejiang provinces, (Sun, 1981) evaluated the courtyard space and the impacts of environmental elements such as sunlight, water, and soil on Siheyuan traditional houses. Researchers across the globe had supported the feature thermal ease and its role in the building performance. Also helped the advantages of improved micro-climate within the building supporting comfortable inner spaces (Aldawound, 2008). Using environment for Visualising Images and Met software's, Ghaffarianhoseini et al. (2018) evaluated the thermal response of the courtyard houses in particular with the shaded portions during hot climates of Malaysia.

With reference to natural ventilation availability, Jamaludin et al. (2014) had observed the residential college building having internal courtyards with altered ventilation approaches. An experimental project in Saudi Arabia with an inner courtyard model for testing the response of the structure for hot and harsh climate conditions, a 
numerical analysis was performed to the courtyards present in Italian climate zones by considering the factors like width and height of interior rooms (Enrique, 2017). On the other hand, to analyze the effects of the courtyard buildings having different shapes due to solar heat gained in different locations. Veerendra et al., 2018 investigated the solar pathwise heat increase and the behavior of the residential building thorough out the year with the help of a Building Information Model rendered in Revit architecture software. With the help of simulation software, Xu et al. $(2006,2014)$ evaluated the heat and wind distribution in a traditional Chinese building using qualitative and quantitative research methods. A similar study was done in the province of Beijing to study the distribution of temperature and to mitigate the urban heat island effect (Yang et al., 2012). To observe the wind movement, Cao et al. $(2015 ; 2016)$ had simulated a traditional quadrangle courtyard house in the province of Anhui.

\subsubsection{Design Considerations for Optimization}

A Study performed by Xiaodong et al., (2018) had evaluated the performance of the courtyard design of a museum building, located at Jiangsu Province. The study had undergone computational fluid dynamics, integrated code series with parabolic to study wind patterns and flow within the museum, also performed energy simulation with design builder software. The results from the software suggest $19.6 \%$ of buffer areas in the courtyard had an increase in cooling even in the summer season, approximately $22.3 \%$ increase of heat during the winter season.

China has a large geographic area as a whole. In contrast, the design of a courtyard, the concern has to take into account the features like environment, climatic, and other ecstatic conditions of the area to get a better understanding of the location (Khan, 2008). The design of the new construction should undergo the evaluation of weather 
conditions, formations of the courtyard, and its location to incorporate in the province. Secondly, the design should concentrate on more initial plans and strategies in concern with aspect ratio and buffer zones (Rajapaksha et al., 2003).

\subsubsection{Scope for Field Investigation}

The field investigation is treated to be an essential part of a good understanding of the project. The initial agreement includes cultural beliefs followed at the province, location attributes, physical parameters evaluation related to the designed local courtyard, direction of the wind, solar intensity throughout the year, and the climatic conditions (Cannistraro et al., 2015). During the entire process of field visits, the complete understanding of the building can provide insights, as mentioned in the paragraph, additionally with the type of building materials used in the period. Also, the parameters like "hutong" and dimensions are gathered (Xu, 2005).

\subsubsection{Designs for Optimization}

The integral part of the design has the influence of the courtyard layout on heat gained through solar radiation to the building, and the flow of natural air can transfer the heat to the residential areas (Moosavi et al., 2015). The heat pertained within the building during the summer seasons can be diverted with the help of natural ventilation flow between the spaces that can improve the comfort of inmates. The circulation of wind with fresh air can help to vent out the bad breath, eventually support the improvement in physical and mental health (Taleghani et al., 2015).

Delgarm et al. (2016) addressed the use of optimization and suggested an algorithm to identify the problem within the design using the Energy Plus simulation. Further researchers around the world made an effort to focus on techniques for optimization under the architectural point of view. For example, Waibel et al. (2019) proposed 
single- objective algorithms for optimization, and for evaluating the parameters within the architectural design, Ekici et al. (2019) had used the swarm type computational architecture. For better study and to retrieve more efficient results, more than two optimization algorithms are used. Gou et al. (2018) had proposed passive design optimization for buildings to have an intensive understanding of the heat environs and balance energy consumption. Multi-objective Optimization (MOO) model was proposed to underpin energy consumption, and other systems are explored for overall optimization.

Therefore, while designing for courtyards the features like natural ventilation, lighting should provide sufficient light and fresh air during the day and less dependent on artificial features.

\subsubsection{Conceptual Design}

According to Oxford English dictionary (2000:156) courtyard building is "an area of ground, without roof, that has walls or building around it, for example in a castle or between houses or flats". The concept of the courtyard house is dependent on the enclosed space being open to the sky and surrounded by rooms on all sides. central courtyard of a house is the most efficient air conditioner for it traps the cold of desert night air, releasing it gradually during the day to adjoining rooms through in-built cluster(Swan, 1991).courtyard house, in addition to its flexibility of orientation, are well protected from the hot, sandy winds and outside air pollution(Bukamar 1985).

Set six functions of the courtyard as follows:

- The demarcation of limits of the property;

- The definition of a place of privacy for the family;

- The unification of spaces and elements in a house; 
- The provision of circulation elements;

- The creation of a garden or cool place;

- The promotion of ventilation.

\subsection{Context Analysis}

The theory of Lynch, (2001) regarding Good City Form will address my research's objective regarding sustainable designing of the residential buildings in Beijing with an objective to achieve environmentally sustainable urban planning. Kevin A. Lynch was an American urban planner and author of many books. He was one of the pioneers on mental mapping and was quite famous for his work on the perceptual form of urban environments. Lynch evaluated the concept of urbanization not only from the perspective of physical developments, but he explored the factors of sustainability, including both from the perspective of environment and from the preservation of the traditional values of a city. Using the work of this theorist would help in understanding the designing and reconstruction of traditional courtyard houses in such a way that the traditional values can be retained along with objectively achieving the environmental sustainability and healthy urbanization.

The theory of Sitte, (2013) regarding the art of building cities will help me in addressing my research objective related to investigating the implications of construction and architectural practices adopted in the past on the development and building of traditional courtyard houses in Beijing. Camillo Sitte was an Austrian architect, urban theorist and painter, whose work plays a significant role on land use and urban planning regulations in the European region. The work of Camillo Sitte would help me in developing understanding regarding the construction and architecture practices used by the ancient Chinese people, especially concerning the 
construction of courtyard houses. Though majority of this theorist's work is based the theory of Trancik (1986) regarding the Lost Space will help me in addressing the core objective of my study that is to examine the impact of QCGS on residential buildings in Beijing. Roger Trancik is a practitioner and educator of the urban design and planning. He has written three national award-winning books and written more than 40 professional urban planning studies, scholarly papers and journal articles.

The theory of Roger Trancik focuses upon sustainable planning of urban cities, as it has been observed that in building and construction of towers, plazas and even houses in urban cities, designers and constructors usually leave extra spaces on sides of the buildings or in front of the buildings for purpose of parking, which he called as lost spaces. As these spaces are on no use and also don't add anything positive to the buildings. Similarly, he states that the buildings developed in urban cities are comparatively congested with poor flow of light and wind. The work of Roger Trancik will help me in addressing and critically evaluating the Quadrangle Courtyard Green Simulation Approach that is the core objective of my study and build understanding regarding the efficient use of these extra/lost spaces in the form of gardens that were prevailing in the traditional courtyard houses.

\subsubsection{Summary}

The work of all the three mentioned theorists would have considerable implications on the topic of my study and these all would significantly assist me in achieving the three key objectives of my study. The work of Lynch would help me in building an informed approach towards suggesting sustainable design in the project, while the work of Roger Trancik and Camillo Sitte would enable me to address the prevailing problems in the designs of contemporary urban cities including lost space and 
ineffective arrangements for light and wind flow into the contemporary houses. Similarly, it would also help me in retaining and establishing the sustainability of contemporary buildings in Beijing in terms of cultural and traditional heritage. With the help of critical input of these theories, the thesis would therefore incorporate the features from the case study become capable of recommending a highly sustainable and healthy design for residential houses with an effective light and wind ratio, which was used to be prevalent in the traditional courtyard houses; however, the designs would also incorporate the aspects of urbanization to offer a stable and competitive lifestyle for the residence.

\title{
2.6 Case Study
}

\author{
- Collective Living \\ Designer: Fanhao Meng (Project Partner), Min Zhu, Xiaocheng Zhu, Qiang Li \\ Location: Dongziguan Village, Fuyang District, Hangzhou, China
}

Date: 2016

The buildings in the project are developed with vernacular style of courtyard typology, while keeping alive the local traditional morphology of the area. Six different buildings are developed in a such manner that it gives the structure of a courtyard and the designs were specifically developed keeping in mind the light and wind ratio of the traditional courtyard houses, so that each portion or building can get appropriate exposure of sun light and wind. The design of this project shows high inspiration from the theoretical development and understanding of Kevin A. Lynch theory of Good City Form because this project effectively addresses the concerns of increasing population and urbanization with the objective of sustainability and traditional values. The project specifically addressed the modern city form concept presented by Kevin 
A. Lynch, because it not only provided a sustainable solution, but also used an area of 15,300 square meters for construction of 50 houses with quite sustainable design and reasonable accommodation facility. The design of this project explores the best usage of glass, steel and bricks that ensured quite effective ventilation and thermal performance. This project specifically addresses my research's objective regarding sustainable designing of the residential buildings in Beijing with an objective to achieve environmentally sustainable urban planning.

(Source:https://www.archdaily.com/802369/contemporary-rural-cluster-dongziguan-affordable-housi ng-for-relocalized-farmers-in-fuyang-hangzhou-gad)

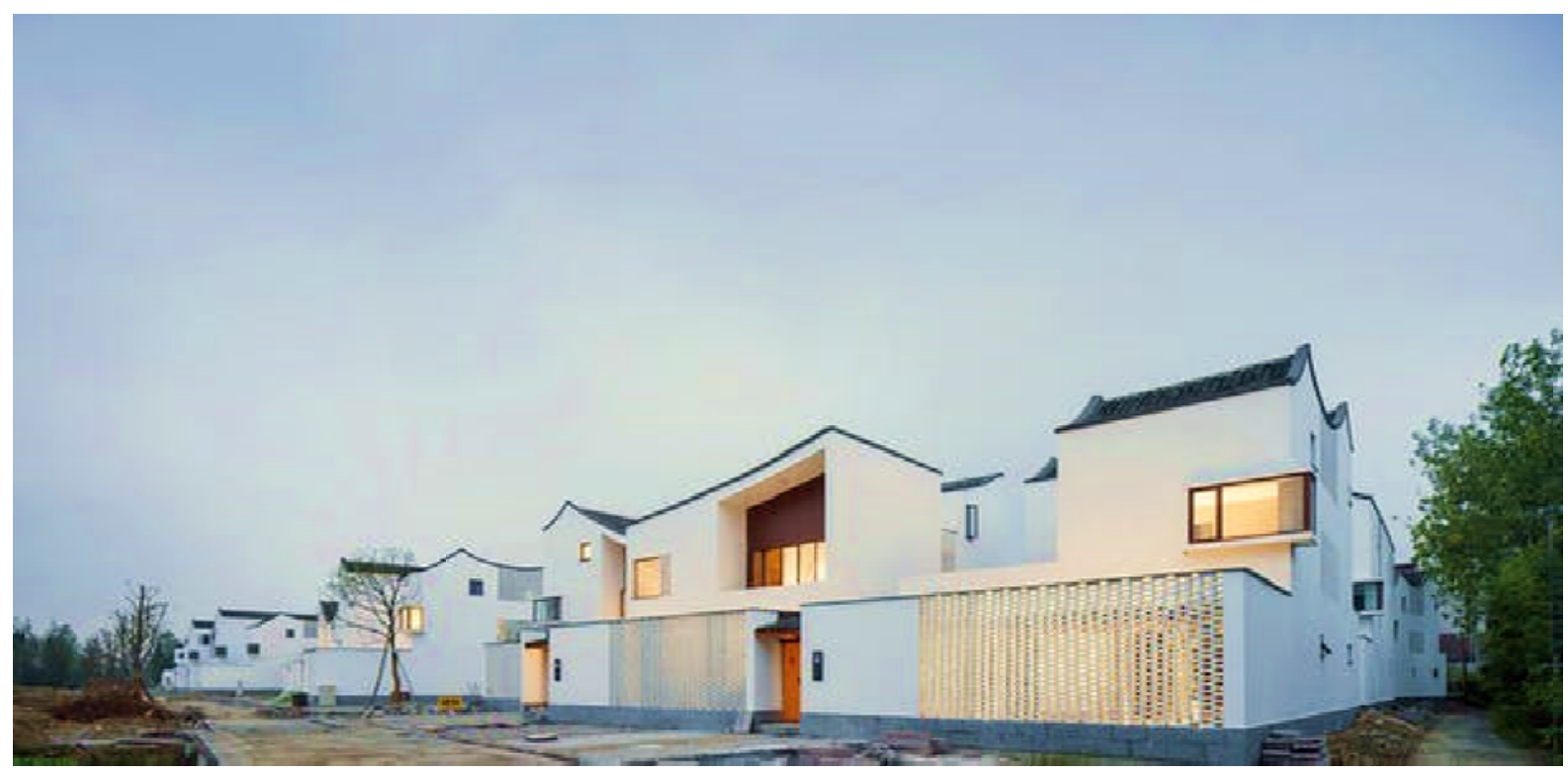

Figure 5. Dongziguan Village (Li, 2016) 


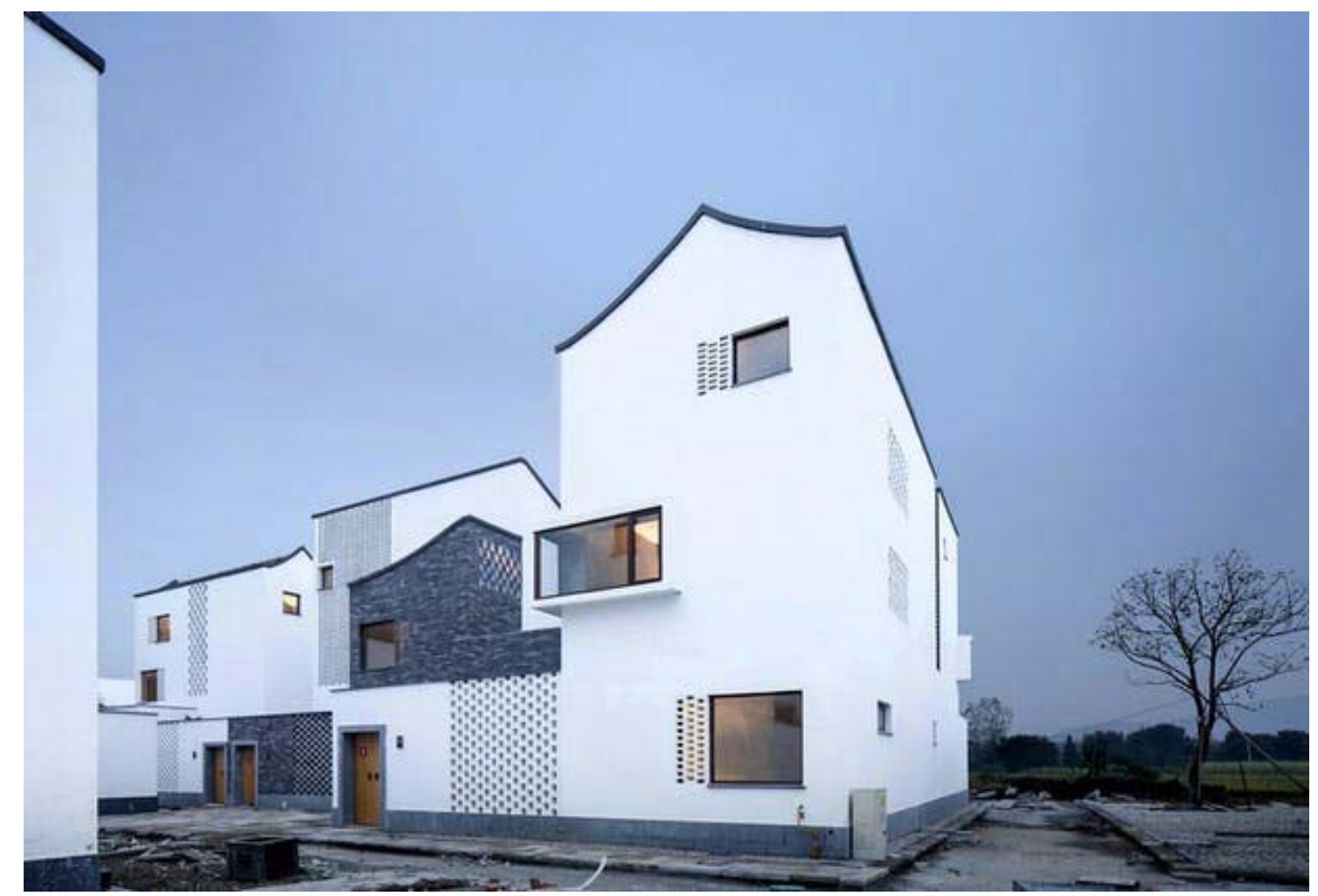

Figure 6. Dongziguan Village (Li, 2016)

- Twisting Courtyard

Designer:ARCHSTUDIO

Location:Paizihutong, Dashilar Area,Beijing, China

Date: 2017

This house is an up gradation of the traditional Siheyuan. The up gradation was aimed to bring improvement into the infrastructure for meeting the modern lifestyle needs. It provides a broader perspective to see the traditional Siheyuan houses and get rid of stereotyped and solemn impression of such traditional houses. The basic design of the house was kept that of the courtyard, while improvements were made in terms of making it more sustainable and exposed to the required concentration of heat, ventilation and light. The design of this project closely interprets the theoretical preposition of Camillo Sitte, who presented a theory regarding the art of building 
cities with an objective to transform and develop the new cities by keeping the traditional culture and values of the locality alive. The design of this project also significantly correlates with one of the objectives of this study that is to investigate the implications of construction and architectural practices adopted in the past on the development and building of traditional courtyard houses in Beijing. The architect has effectively used the lay out and basic concept of traditional courtyard houses and incorporated several modern architecture developments to make it more competitive and viable for the modern contemporary needs of the society.

Source:https://www.archdaily.com/873630/twisting-courtyard-archstudio)

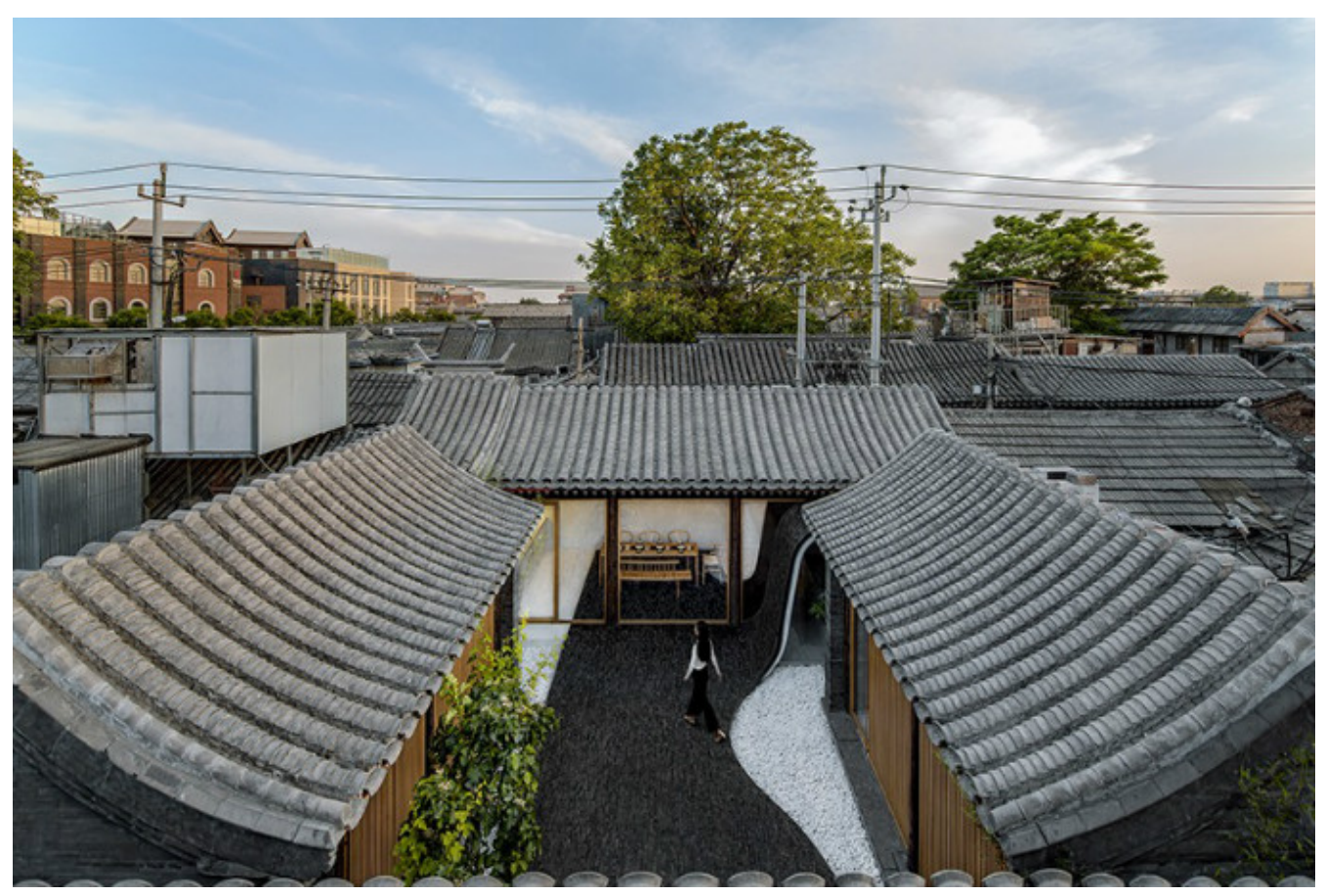

Figure 7. Twisting Courtyard (Weiqi, 2017) 


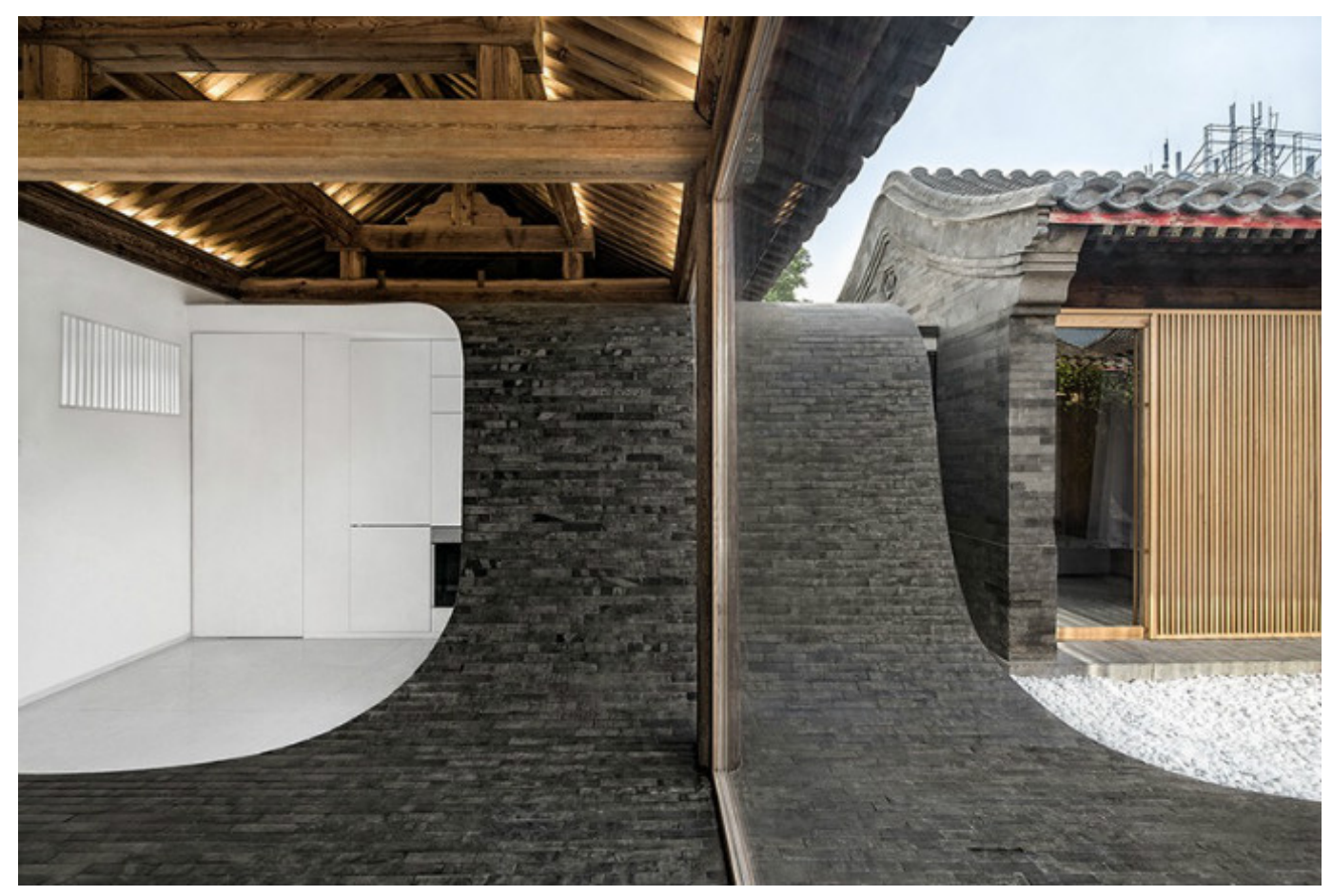

Figure 8. Twisting Courtyard (Weiqi, 2017)

- Zhu'an Residence

Designer:Yang Zhao, Peigen Shang

Location:Xizhou, Dali, Yunnan Province

Date: 2016

This project shows a typical up gradation of a traditional courtyard house for a single family. The house covered a total area of 800 square feet. A number of variations to the traditional courtyard houses are made in this project ranging from variations in material used to the overall layout and design of the house. The house comprised upon nine private quarters for the resident couples. The design project closely interpret the theoretical preposition of Camillo Sitte and Roger Trancik because on one side it is a perfect representation of the preservation of heritage and culture with some modern 
developments to make the house more sustainable and on the other hand it also addressed the lost space concepts effectively through green belts and plants on the extra spaces and also gives a clear purpose and objectivity top each corridor and extra space. There is a perfect ventilation and thermal/sun light exposure given to this house, which makes it more sustainable. The design of this house effectively addresses the core objective of the research study that is to examine the impact of QCGS on residential buildings in Beijing. Though the house is not located in Beijing, but it gives a clear and concise input to the idea of sustainable transformation of the modern buildings into the traditional and highly sustainable houses.

Source:https://www.archdaily.com/783906/zhuan-residence-yang-zhao-peigen-shang?ad_source=sea rch\&ad_medium=search_result_all)

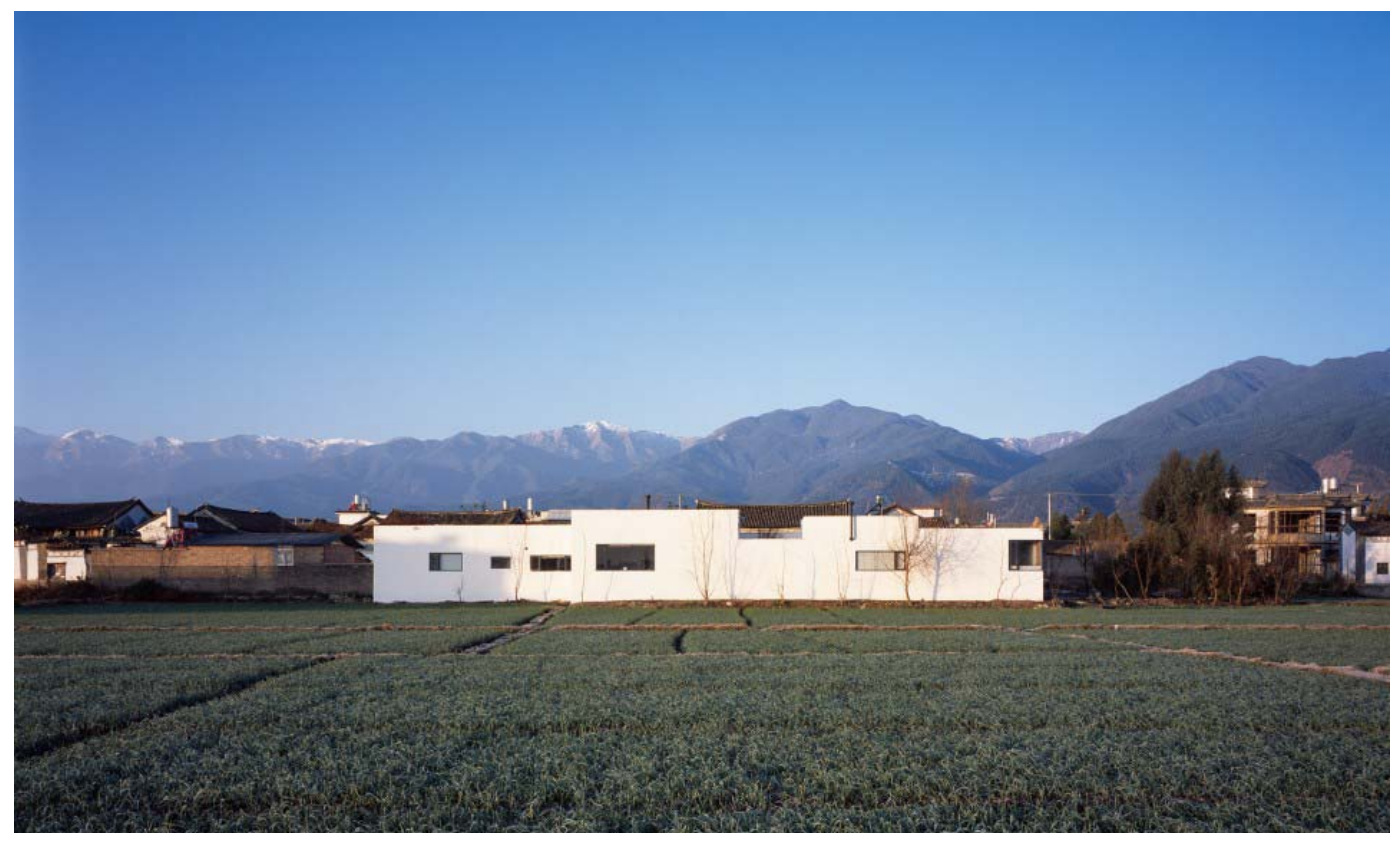

Figure 9. Zhu'an Residence (Hao, 2016) 


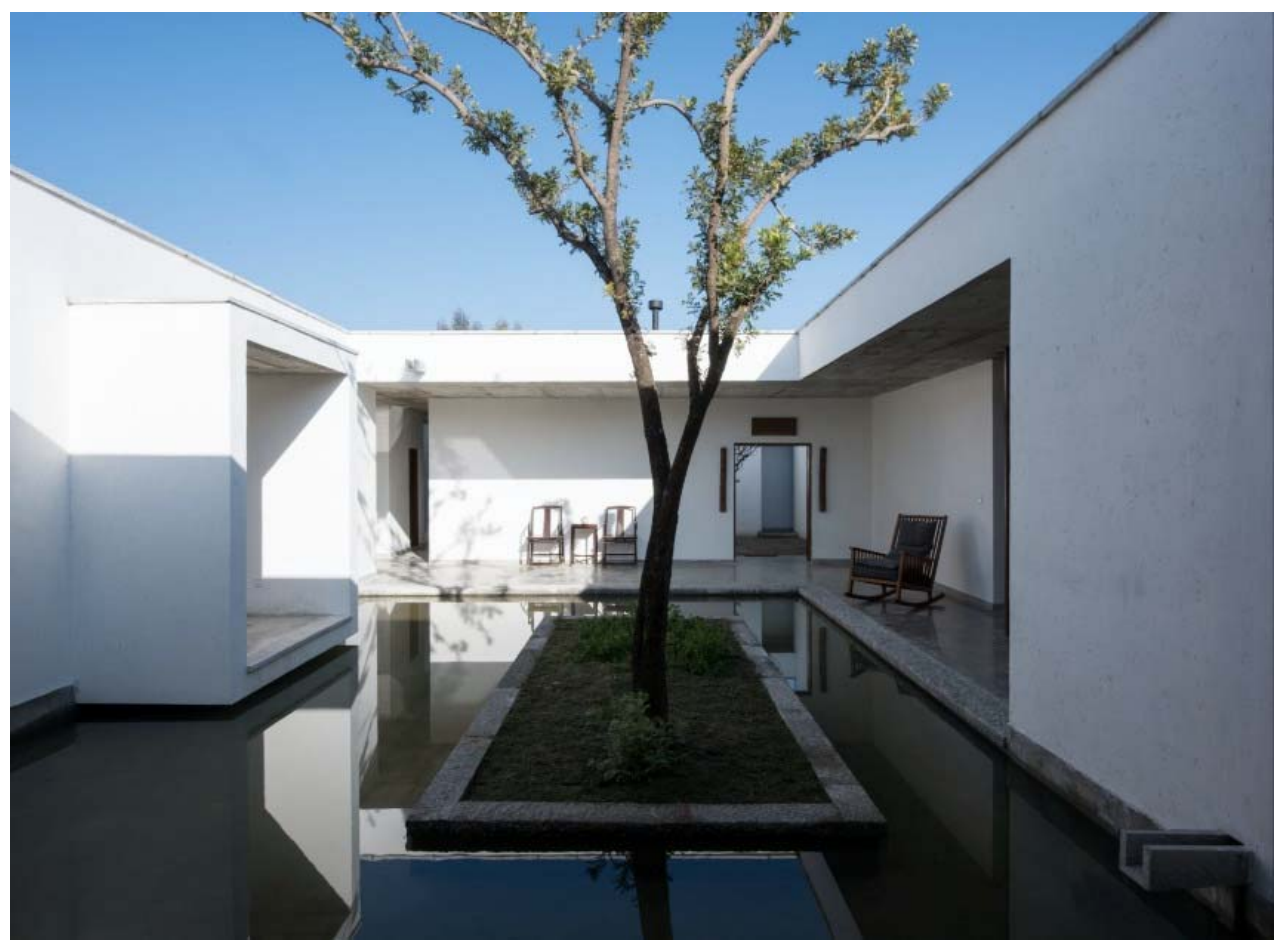

Figure 10. Zhu'an Residence (Hao, 2016)

\subsection{Summary}

This chapter had undergone a study of various features and types of courtyards constructed in the present day. Most of the case studies addressed in this chapter are rendered to be the modified form of the traditional Chinese Courtyard style. The case study - "Collective Living" shows the best usage of window ratio of the courtyard houses and involved urbanization and population growth. The case study - "twisting courtyard" involved the modern architectural styles with the blend of ancient style can be seen. Besides, it addressed the essential elements such as ventilation, heat, and exposure to light. Finally, with Zhu'an Residence, the selection of construction materials also preserving the tradition and aspects are studied.

The case studies chosen for this study had provided a major impact and ample 
information. The objectives identified for this study are monitored to be an essential part, and the case studies identified for this study had provided relevant information. 


\section{Site Analysis}

\subsection{Introduction}

In this chapter, the selected study area is introduced, and the features are analyzed. Also, will identify the site visit findings in terms of living space, living conditions, the population of the area, and its present situation was presented. After that, characteristics that are essential to the courtyard house are examined. The fellow researcher helped to explore the study area because of COVID-19 and restrictions by the local government. Only the key areas explored; all the photographs are taken during the preliminary site visit to the location. Due to lockdown and social distancing, the location was restricted not to entire. Based on the site visits, a detailed map is prepared to point out the location.

\subsection{Study Area}

These three areas are also mainly residential areas. They are Changchun Road Distinct, Dazhlan Distinct, and Lanluogu Road Distinct. Due to the large area for investigating, only two small roads are selected for data collection in each area. They are Tangning Hutong and Guangcai Hutong in Changchun Road Distinct, Tiaozhou Hutong and Cha'er Hutong in Dazhlan Distinct, and Jingyang Hutong and Yu'er Hutong in Lanluogu Road Distinct. 


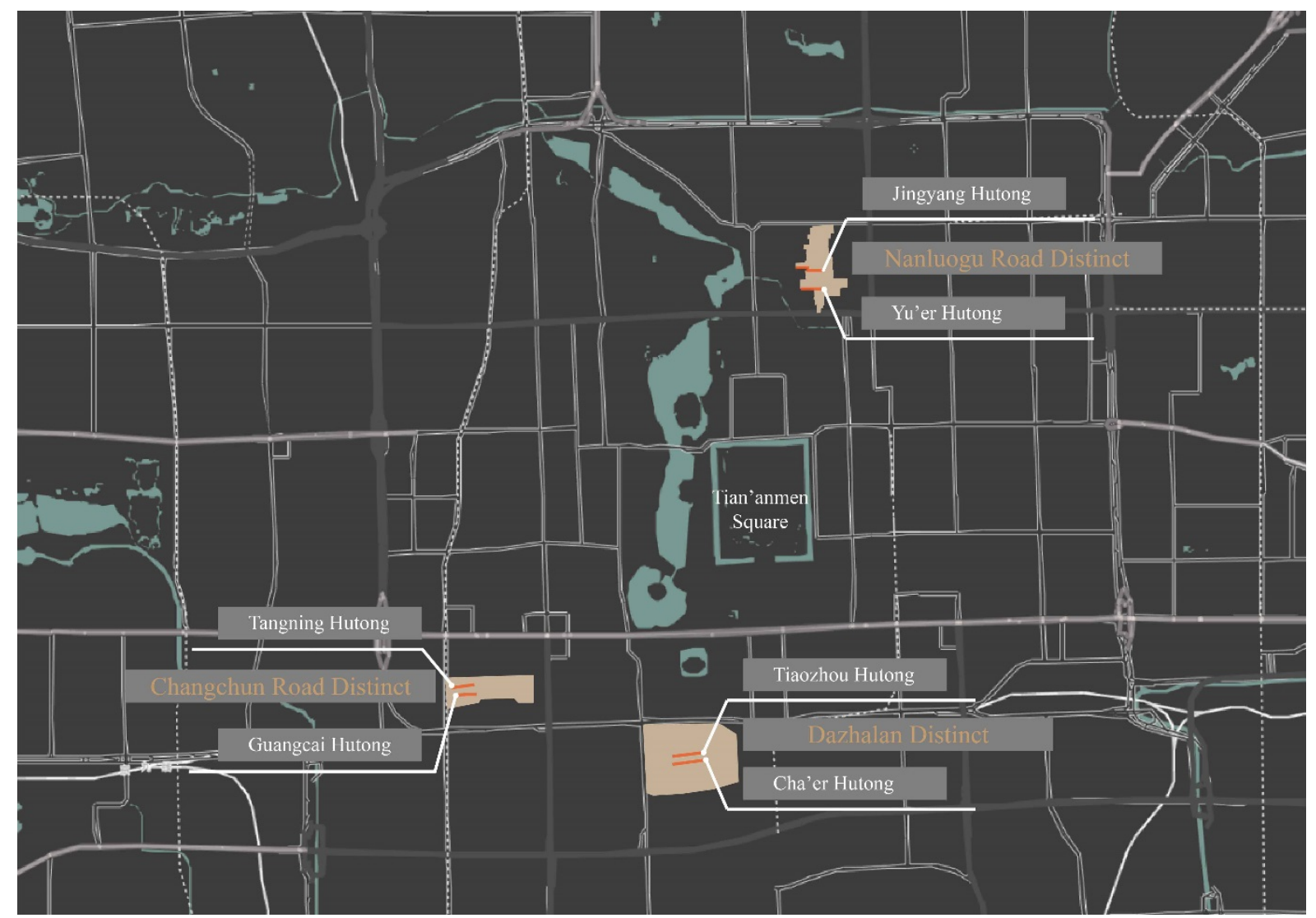

Figure 11. Map of the Research Site

\subsection{Current Situation of Beijing Courtyards (Siheyuan)}

\subsubsection{Illegal Expansion of Living Space}

The traditional courtyard is composed of a "court" and surrounded by the "wall" as the boundary. As a result, the enclosing of the "wall" and the "court" closure limit the possibility of the courtyard space's outward development. With society's development and the rapid increase of population, traditional courtyard buildings gradually began to fail to meet contemporary people's living needs. Residents living 
in the distinct of the courtyard began to illegally build more space in their inside yard to solve the problem of insufficient living space. However, due to the built spaces that do not meet the specifications, these extra built spaces are not only tiny and crowded but also have extremely poor living conditions, which pose safety risks.

The figure 12 below shows theextra built bedroom in No. 8Cha'er Hutong. And figure 14 shows an extra built kitchen in No. 15Jingyang Hutong.
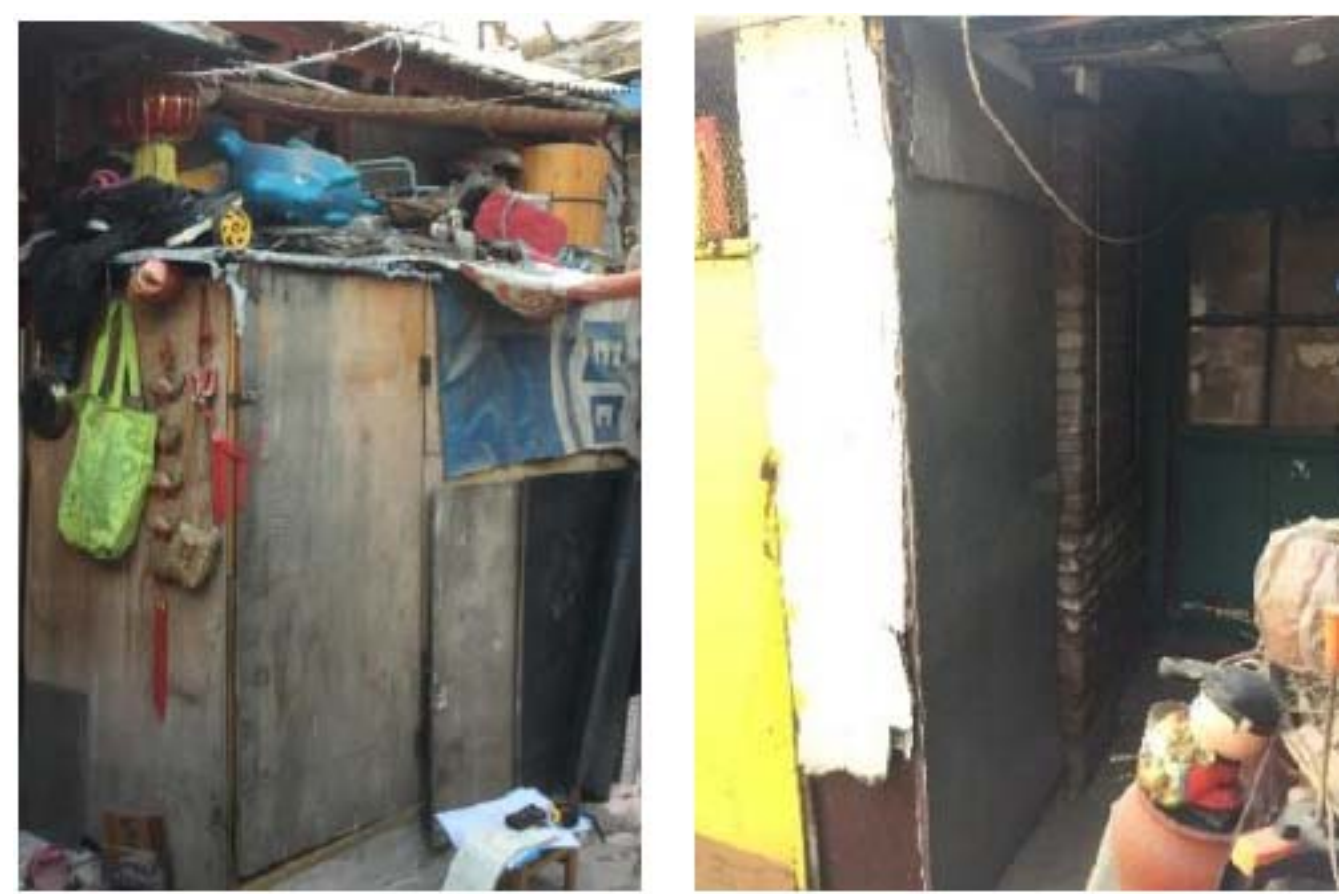

Figure 12. Courtyard House at the No.8 Cha'er Hutong 


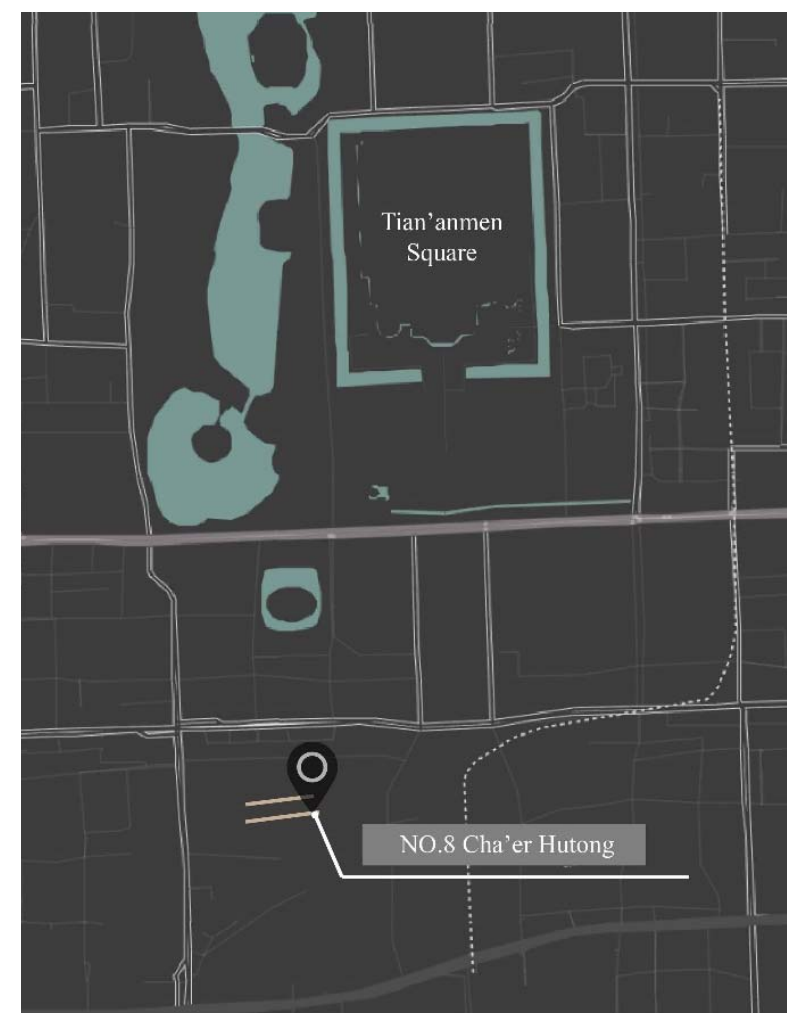

Figure 13. Courtyard House at the No.8 Cha'er Hutong

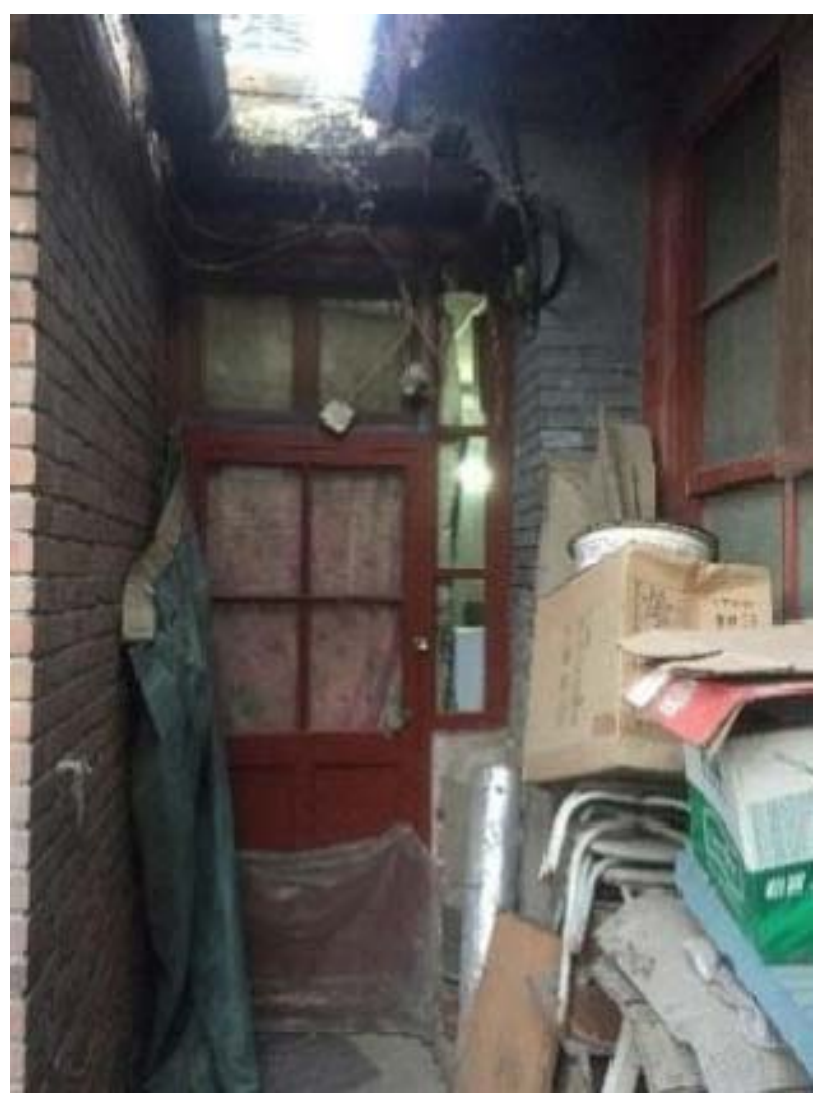


Figure 14. Courtyard House at the No.15 Jingyang Hutong

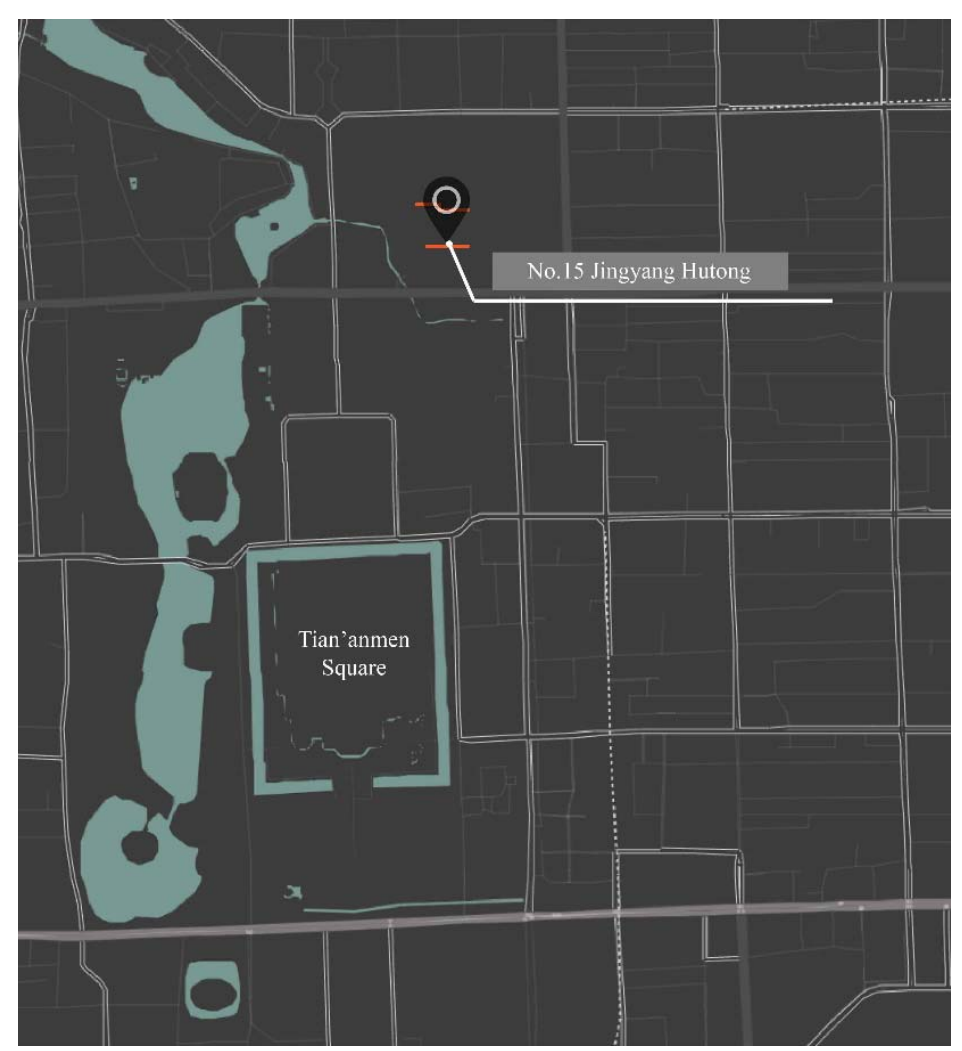

Figure 15. Courtyard House at the No.15 Jingyang Hutong

The courtyard houses' indoor yard is occupied by various illegally extra built spaces, leaving the only passageway. Besides, most of the siheyuans have piles of debris in the inner courtyard, which shows a shortage of storage space in the original living space of residents.

\subsubsection{Poor Living Conditions}

The traditional courtyard has been built for a long time. Therefore, the indoor and outdoor infrastructure is far from reaching modern standards. It can be summarized in 
the following aspects:

-The sewage discharge in the residential house is the same as the public rainwater pipeline. When it rains outside, the rainwater will be poured into the indoor spaces;

- Since the original structure of the house is not equipped with an inlet pipe, each unit has no restrooms, so residents can only use the public toilets;

-Due to structural problems, the shower can only be installed in the indoor yard's illegally built space. When winter comes, the sub-zero temperature often freezes the water pipes, resulting in multiple maintenance and inconvenient use;

-The courtyard houses have poor thermal performance and air leakage from doors and windows.

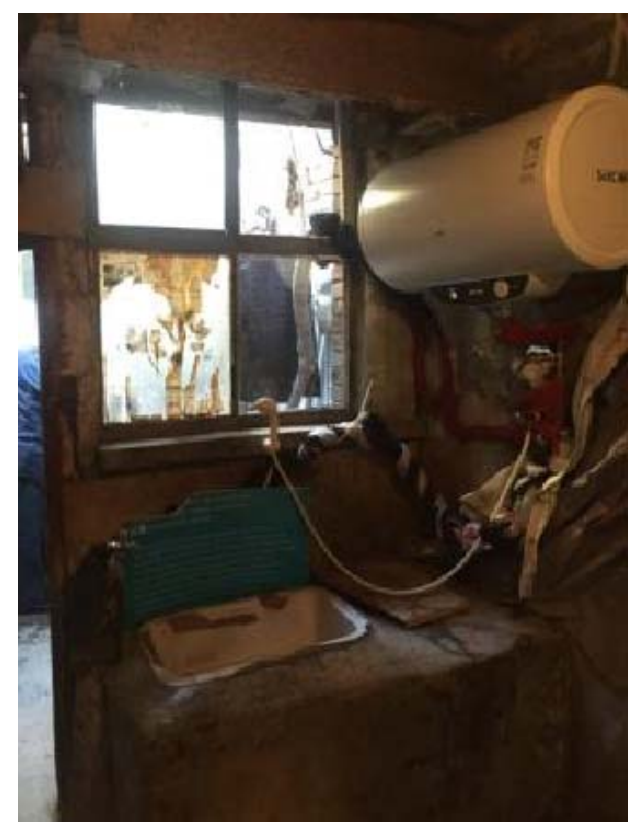

Figure 16. The Illegally Built Shower

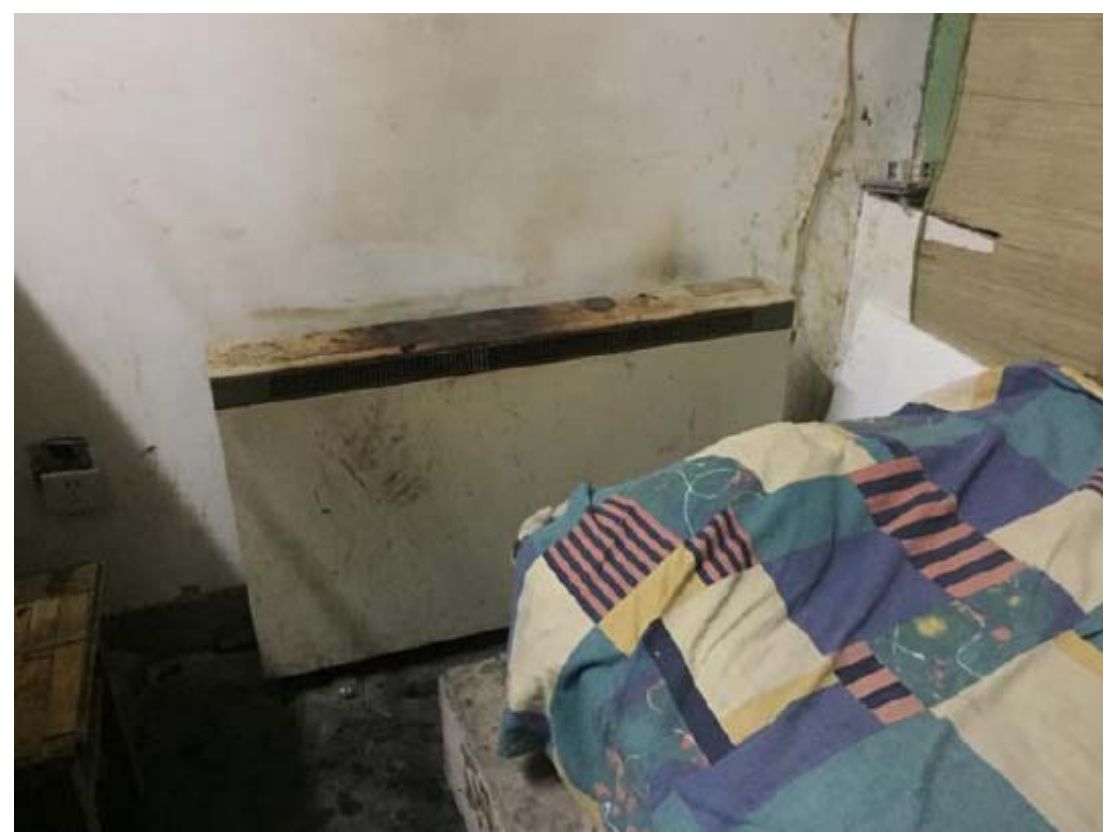

Figure 17. Courtyards House's Bad Indoor Environment 


\subsection{Current Situation of Courtyard Houses in Cha'er Hutong}

Cha'er Hutong is located north of the center of Dashilan District. The whole street is about 2.4 meters long and 4.5 meters wide. This area retains the longest and most complete courtyard style. Therefore, after investigating courtyard buildings' living conditions in the three significant distinct, Cha'er Hutong was chosen to collect data from inspecting the current situation of preservation of traditional courtyards.

\subsubsection{Population}

The following data are from Beijing Statistical Yearbook (2019). There are 35 courtyards in Cha'er Hutong, 9 of which are non-residential residences, accounting for $26.5 \%$ of the total courtyard buildings. These houses were transformed into clinics, architectural studios, and children's libraries. On the other hand, there are 26 residential courtyard buildings, but has 41 households live here. Since there is a school near Cha'er Hutong, most people living here are elderly and children under ten years old. Although the children of the elderly work in Beijing, they usually have a limited time living in the courtyard because they have to work.

\subsubsection{Retention of Traditional Courtyard Houses}

\subsubsection{Roofing}

The traditional courtyard house's sloping roof design helps slow down the cold air entering the inner spaces in winter and also accelerates rainwater's time staying on the roof in the rainy season. However, among the 26 residential courtyard buildings, half of the building roofs are aging, and roof tiles fall off, which directly leads to roof water seepage. Some residents cover the roof with canvas and then use bricks to press 
the canvas to prevent the canvas from being blown away by the wind. However, the roof design initially only considered the load-bearing capacity of the tiles. Placing bricks would increase the risk of roof collapse.

\subsubsection{Indoor Yard}

The traditional courtyard building has an indoor garden. The existence enhances of the inner yard enhances residents' living environment and allows them to get mental and physical health. However, residents have taken up the indoor yard space to expand the living space, which caused the living environment to deteriorate sharply.

The size of the illegally built space in the courtyard houses is determined according to their own yard size.
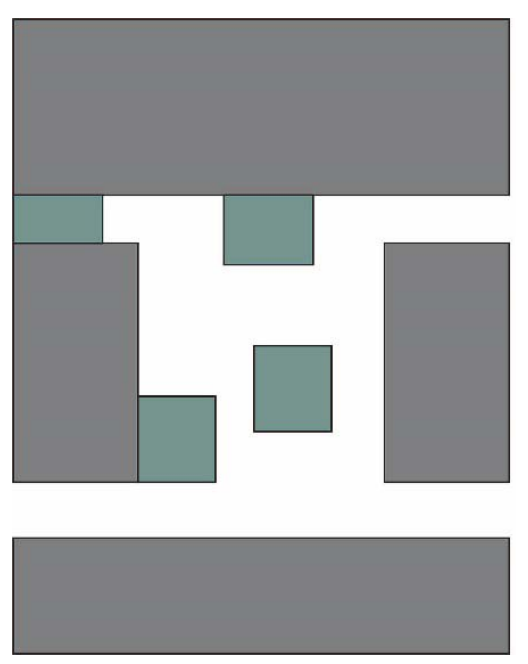

Figure 18. Illegal building when the courtyard's aspect ratio is $0.9-1.3$.
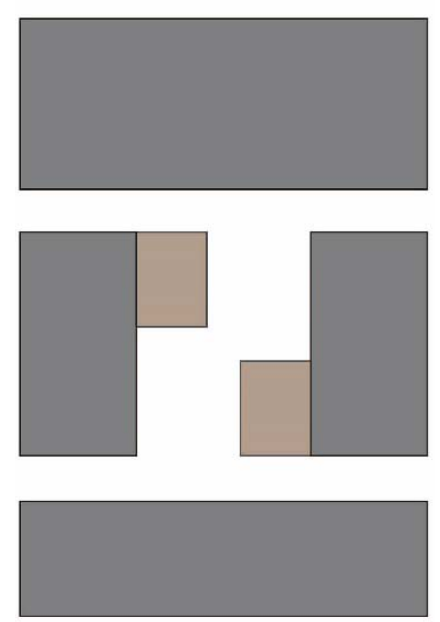

Figure 19. Illegal building when the courtyard's aspect ratio is $0.7-0.8$.

\subsubsection{Indoor Heating in Winter}

The heating supply in winter in Beijing is from November to March of the following year, and the daily heating time is from 9 pm to $6 \mathrm{am}$, a total of 9 hours. Residents can choose whether to turn on the heating. Each hour of heating needs to pay 0.4 yuan for electricity. Among these 26 households, 23 households are satisfied with 
the indoor temperature comfort in winter. But three households are older people living alone, and they generally feel cold during the day without heating.

Since the bathing place is in the illegally built space in the inner yard, this space is not covered in the government heating system. Therefore, one-third of the residents have installed electric heating in the space. Electric heaters generally consume more electricity than government heating installations.

\subsection{Summary}

Three major courtyard building clusters in Beijing were inspected to know the traditional courtyard buildings' general living conditions through site visit. Simultaneously, it carefully inspected 26 residential courtyard buildings on Cha'er Hutong, including the aspect of the population, the renovation of courtyard buildings, and internal residents' living conditions. To understand the need of architectural practices promoted by traditional courtyard houses in Beijing. Also identifying the advantages of QCGS for renovating residential buildings. Finally, to promote sustainable environment and healthy living in the urban environment. 


\section{Research Methodology}

\subsection{Introduction}

Phoenics is the on its kind of a commercial software package used for computation of fluids and heat transfer. In this chapter Phoenics software is deployed for calculation of wind movement for a designed courtyard building. Phoenics is a reliable, cost-effective C.F.D. program with proven track record for simulation scenarios involving fluid flow, heat or mass transfer, chemical reactions and combustion for a wide range of applications.

Further, Green build studio is an online plugin from Autodesk Revit platform used for Green simulation technique. Autodesk green build studio is a flexible cloud-based service that allows user to run building performances simulation to optimize energy efficiency and to work toward carbon neutrality earlier to the design process. Green build studio will help to extend the ability to find the design of high-performance buildings at a fraction of the time and cost of conventional methods.

\subsection{Research Design}

In this chapter, a model was designed based on traditional courtyard houses in Cha'er Hutong, and conducted wind movement simulation around the courtyard building and simulation with age of air around the courtyard building. For Phoenics 2019 version software is procured from CHEM manufacturers.Later Green simulation for the Best models obtain at the above wind simulation was undergone through Green build studio. 


\subsection{Simulation}

This study's literature review allowed us to explore the software packages available to analyze the existing features available with the study building. Also, the scope of using the software's like Phoenics and Green Building Studio. The reviewed software in the literature review are commercial software packages available in the market and used extensively for various commercial buildings like office and institutional. The software can render the desired building site, the developed building model with platforms like Revit Architecture \& structural allows analyzing to achieve sustainable building designs and developments. For this study, the Phoenics and green Simulation studio are selected to retrieve the features like ventilation requirements and airflow within the courtyard building and energy consumption by all means.

\subsubsection{Phoenics Simulation}

Allegrini et al. (2013) performed study using Phoenics software for wind tunnel. $\mathrm{Li}(2016)$ had conducted analysis and simulation for campus building to find wind and thermal environment. This study had utilised the reference of previous studies to implement the simulation and analysis for the chosen study. In this study, Phoenics software is used, the VR-Editor pre-processing is done for the court yard building. Further steps involve with the options from solver for simulation and VR-Viewer for post processing. V.R. in indicates virtual reality. VR-Editor and VR-Viewer is also coming under V.R.- Environment. The files in VR-Editor have to be saved in Q1 file format, VR-Edtior is used to give input data in the main menu such as geometry, model, properties, numeric and initialisation of the of Q1 file. In object menu the input needs to be given such as plate, inlet, outlet, wind, wind profile and also importing 
CAD file of the building drawn in the AUTOCAD software along with its geometric location. After completion of giving input data, with the help of solver the simulation could run to derive results. VR-viewer is used to view the results, after the completion of simulation the software will show results of pressure of the air, velocity of air, temperature of air and age of air as shown in the below figure. We can visualize results in contour and vector format for better virtual representation.

\subsubsection{Green Simulation}

The energy simulation conducted using Green Building Studio were utilised by various researchers for finding the life cycle analysis of the different types of buildings. Veerendra et al. (2018) had performed energy simulation for aninstitutional building and found life cycle energy and found the energy cost of the building. For this project initially, the building needs to be drawn with the help of Revit Architecture software, later the Revit model available in gbxml format file can be generated. Further step consists of exporting the file to generate the location and energy analytical model.

Thereafter, the steps with open the Autodesk Green Build Studio webpage and sign in with Autodesk registered account. Get into 'MY projects' segment, click on the utility information and update the required information for the project information. Then again return into the project segment> click on the 'create new project'. Later give the project name, building type and location. > click on actions and add gbxml file.

After, completion of loading it run's automatically and generates results for the project. 


\subsection{Data Analysis}

To identify the suitable courtyard house of the study area, three models are developed as below such as base model, model-1 and model-2. In this section, three models are generated using Revit Architecture. Later, three models are analyzed in Phoenics software to study the wind simulation. Since the location has the fixed dimensions for the site, the modifications are made to the internal components. The below models are the results are generated in the Phoenics software.

- Base model

The base model is the most common courtyard building in Cha'er Hutong, Beijing. The illegally built space has been removed. The latitude and longitude were at $39^{\circ} 53^{\prime} 48.0^{\prime \prime} \mathrm{N}$ and $116^{\circ} 23^{\prime} 26.3^{\prime \prime} \mathrm{E}$. It consists of two pent houses at east and west and a main house at the north and south. Bathroom was located at S-W corner and kitchen at the N-E corner. The width and length of the court yard is about $15.46 \mathrm{~m}$ and $21.21 \mathrm{~m}$. The width to length ratio of the courtyard building is $1: 1.37$.The average wind speed range at location at winter season is about $2.2 \mathrm{~m} / \mathrm{sec}$. The average annual temperature between the year of 2007 to 2016 is $13.5^{\circ} \mathrm{C}$. The base model as shown in the figure below. For the purpose of identifying the best model, three models with specific dimensions are chosen as below.

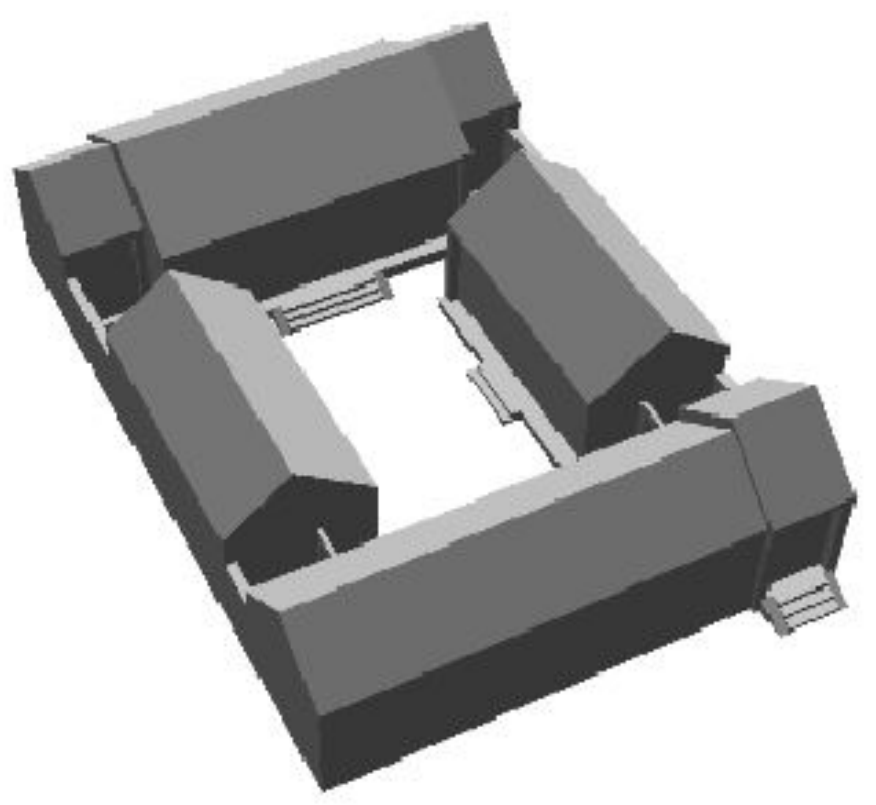


- Model 1

Model 1 has a diverse dimension with base model towards its width. The internal patio of the building is about $1: 1.52$. The length and width of the model 1 is about $21.21 \mathrm{~m}$ and $13.95 \mathrm{~m}$.

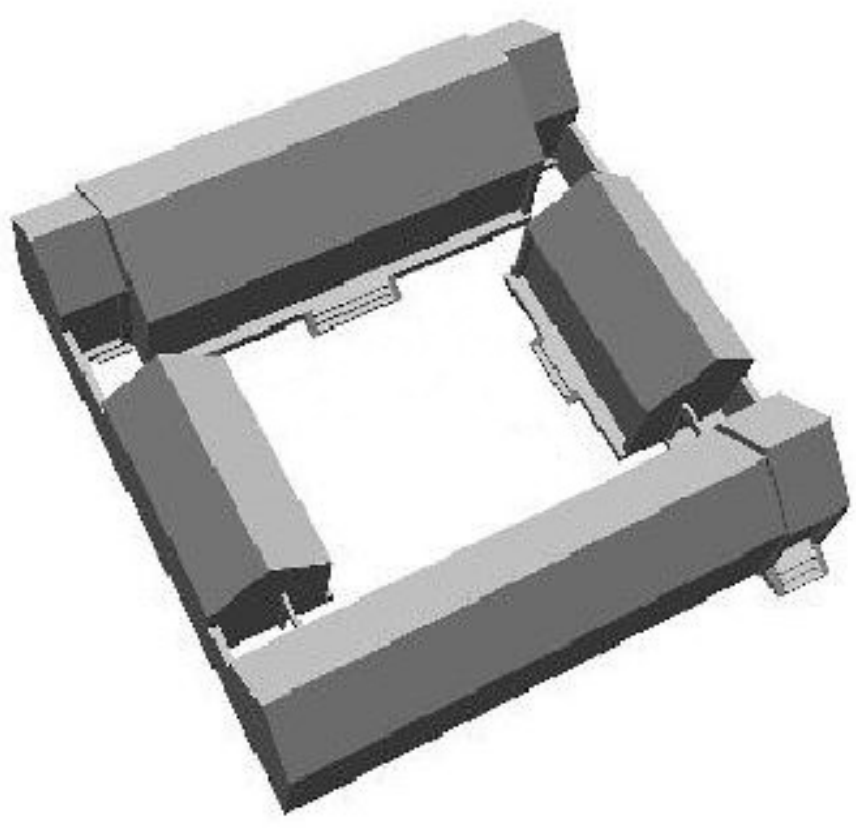

- Model 2

Model 2 has adverse dimension with base model towards its width. The internal patio of the building is about $1: 1.2$. The length and width of the model 2 is about $21.21 \mathrm{~m}$ and $17.68 \mathrm{~m}$.

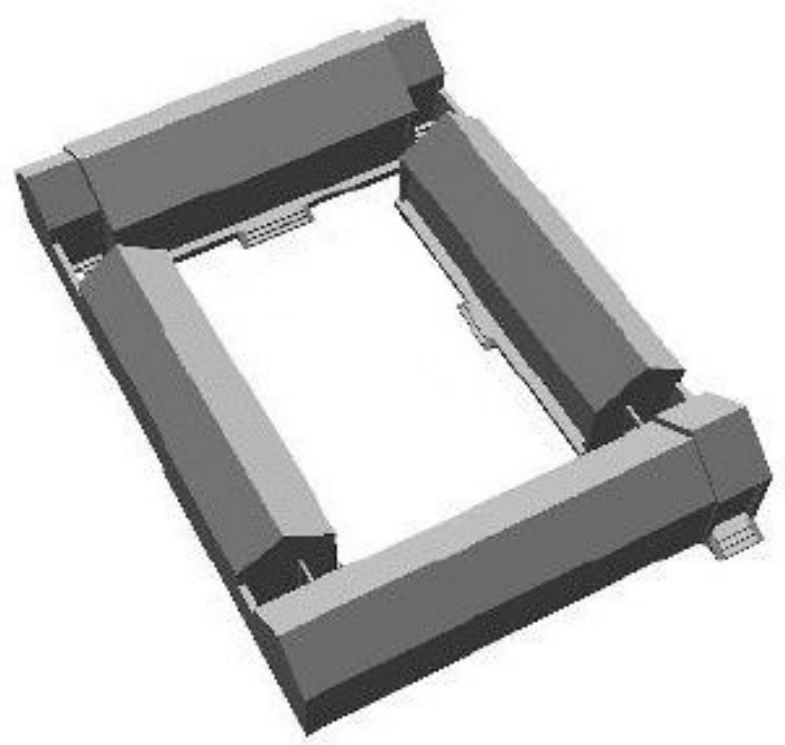




\section{Results \& Discussion}

\subsection{Introduction}

Wind simulation has a greater impact on living conditions of the building. Wind profile will maintain the conditions of heating, cooling environment around the courtyard building. Wind profile of higher frequency less than $5 \mathrm{~m} / \mathrm{sec}$ will reduce amount of energy consumption and increases the efficiency of courtyard building. Age of air represents the amount circulation of air.

\subsubsection{Wind Simulation Results}

The simulation results of the outdoor wind environment in the courtyard in winter at a pedestrian height of $1.5 \mathrm{~m}$ above the ground are shown in the table below. 


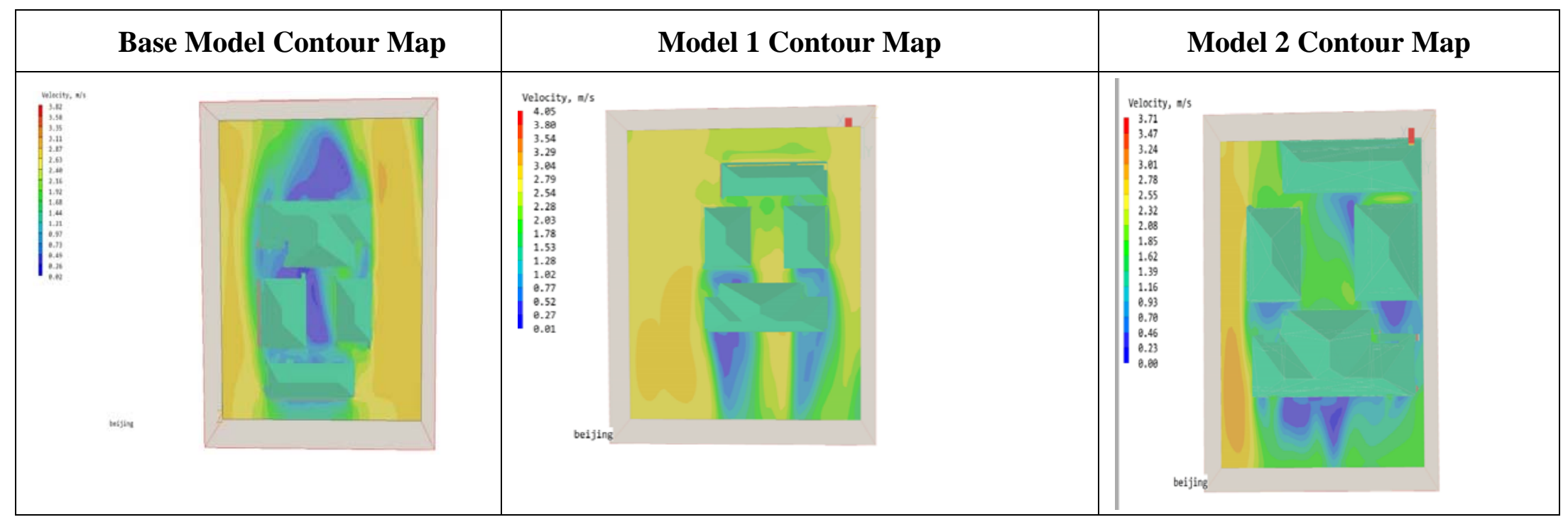

Base Model Vector Map 


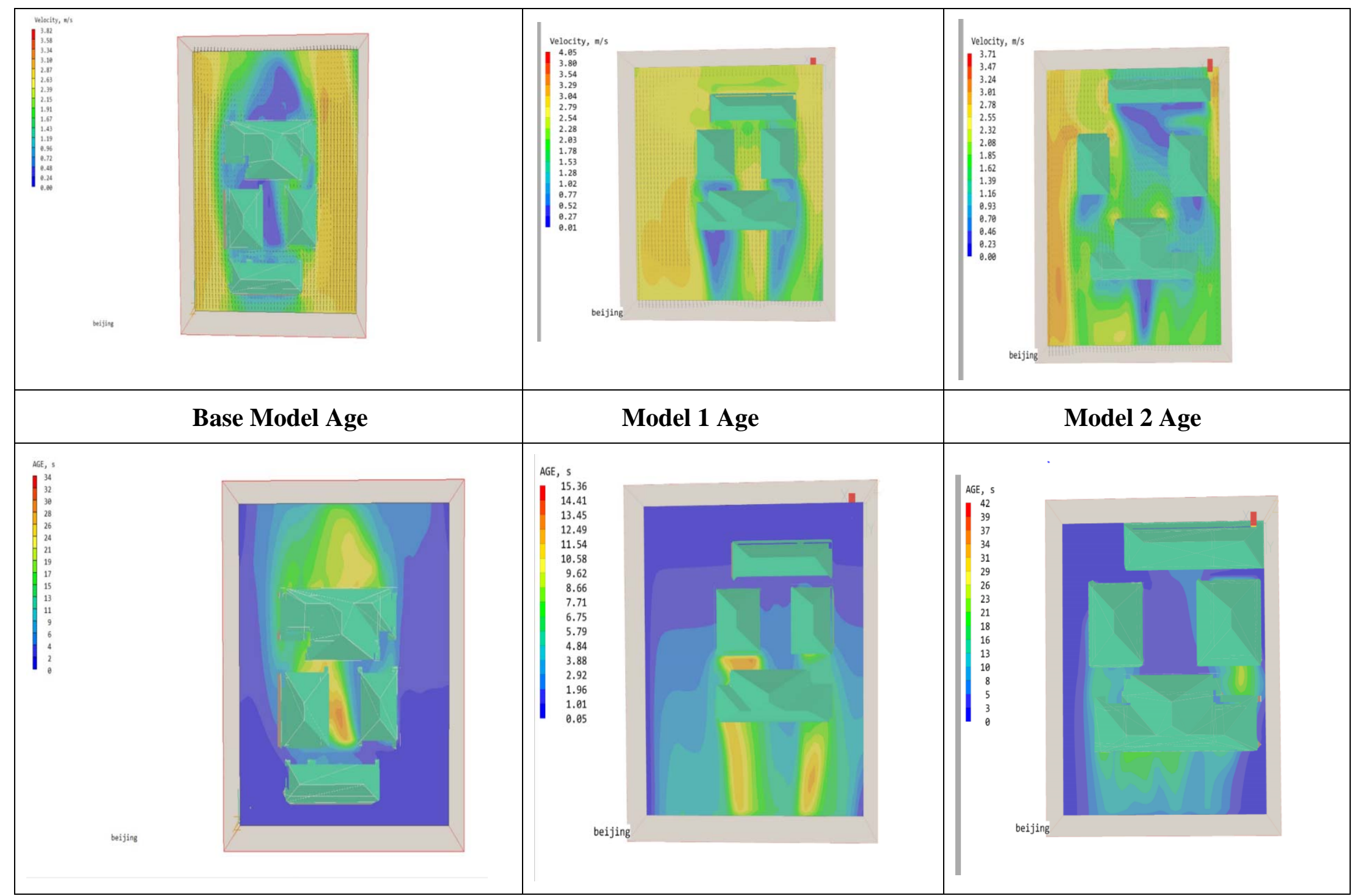


For the base model the wind speed range from 0 to $2.63 \mathrm{~m} / \mathrm{s}$ and its maximum wind speed is up to $2.63 \mathrm{~m} / \mathrm{s}$. Its living conditions were comfortable. The effect of wind on the base model is null. The age of air present at the base model region is about 13 to 21 seconds. Maximum wind speed occurs at the north east corner. The total number of wind whrilpool occurs at the internal patio is null and overall courtyard is one. For the model 1 the wind speed range is from 0.01 to $3.04 \mathrm{~m} / \mathrm{s}$ and its maximum wind speed is up to $3.04 \mathrm{~m} / \mathrm{s}$ with living conditions are comfortable. The effect of wind on the base model is influential. The age of air present at model 1 region is about 4.84 to 9.62 seconds. The maximum wind speed occurs at the model 1 is at north east corner but mostly in east direction. The total number of wind whrilpool occurs at the internal patio is 2 and in the overall courtyard is 5 .

To satisfy sustainable development and adopt the flavor of courtyard construction, it is important to examine and analyze its present status. Concerning the previous studies performed by various researchers, Jang et al. (2017) had performed a study on analyzing the courtyard type building in South Korea. Also, Delgarm et al. (2016) had performed energy simulation for a building optimization algorithm. Another study by Chen (2014) had simulated the outdoor environment with a university building at Tianjin University. With the help of BIM tools and Green Building Studio, Raffee et al. (2015) suggested that assessment of energy performance can provide feasible alternatives to replace or modify the building's overall consumption. Jalaei (2014) proposed that the use of sophisticated software like Green Building Studio and Revit can provide reliable reports on the building's energy performance and life cycle analysis. Xiaodong (2018) evaluated the courtyard design of a traditional Jiangnan Museum located in Jiangsu's province. The project had utilized the PHOENICS software. Using the software, the generated reports of Jiangnan Museum shows that approximately $19.6 \%$ of the heat loads can be reduced during summer and $22.3 \%$ by winter. 
Most of the literature addressed in the above chapters refer to the different locations, hence the factors like environmental, climate, urban population, wind flow, energy consumption will vary accordingly. For the present study, the location chosen was unique and need to analyze in depth to understand all kinds of factors, also the methods chosen for this study are mention to be good approach to perform analysis for both energy and wind flow according to the location. The software's chosen for this study can acquire the right information that can showcase the life cycle analysis and wind flow pattern.

For the model 2 the wind speed ranges from 0.46 to $2.78 \mathrm{~m} / \mathrm{s}$ and its maximum wind speed up to $2.78 \mathrm{~m} / \mathrm{s}$. Its living conditions were comfortable. The effect of wind on the model is not influential. The age of air present at the model to region is about 8 to 18 seconds. The wind speed occurs at the north east corner of the courtyard building. The total number of wind whrilpool occurs at the internal patio is 1 and in the overall courtyard is 3 . The model 3 had showed better results, It can be seen from the simulation results that the wind speeds of the three research models internal courtyards at a pedestrian height of $1.5 \mathrm{~m}$ are all lower than $5 \mathrm{~m} / \mathrm{s}$, which meets the requirements for outdoor wind environment. The wind whirlpool, as an unfavorable factor affecting the wind environment, will increase the local wind speed and affect the courtyard wind.

The comfort of the environment, although the courtyard width-length ratio of the difference model 2 is the same as that of the basic model, the courtyard is the windiest. the upper limit of wind speed and maximum wind speed are both larger than the basic model. 


\subsubsection{Selection of Best Model}

After analyzing three models with the required procedure in the Phoenics platform, the model 2 is preferably the best model. The model 2 was selected in terms of age of the air flow within the courtyard and velocity of the air flow. In all the three models as explained above, air is considered as the influential part, so the maximum wind speed that covers the entire areas is identified. In three models, model 2 had performed well and had showed good coverage of wind to all areas. The comfort of the environment, although the courtyard width-length ratio of the difference model 2 is the same as that of the basic model, the courtyard is the windiest. The upper limit of wind speed and maximum wind speed are both larger than the basic model. The best model selection is undertaken based on the references such as critical review of the case studies and available literature, the right model needs to be picked based on the performance. Most similar previous studies had considered the best model that can satisfy the location parameters like environment, climatic conditions, etc.

\subsubsection{Green Simulation Results}

Green simulation of a building represents the multiple benefits for a building according to the environmental, economic and social retardations. Green courtyard can easily adaptable for the climate and in bio diverse situations. A Green courtyard building has benefits in economical point of view such as cost savings in utility rates. They have a good impact on social things like a good ventilated house can increases the brain functioning and indoor air purity.

Heating, Ventilation, Air conditioning are the essential elements which shows the comfort of the inmates living in the building. With the energy simulation using Green building Studio, it is possible to get life cycle consumption of the 
building.HVAC system normally includes space, area of lights, building elements, electrical equipment and their respective loads etc. Daylight is a mix of both natural sun light and its indirect usage at day time. The ventilation passes through the internal spaces of the building and its helps in health conditions as well as growth of a vegetation in the central courtyard. The objective of daylight insertion into building to minimize the to reduce manmade lighting costs and lowering the HVAC load on the building. Additional to these, inmates have a natural tendency towards daylight that mostly impacts the wellbeing, production and mental satisfaction of the resident.

These are the results obtained from thegreen energy analysis done over the webpage of the Green Building Studio software. The results obtained are energy consumption, HVAC load consumption, ventilation analysis.

\subsubsection{Energy Result}

A direct representation for amount of sustainable energy used for a building. Above figure represents the amounts of electrical load consumed by the detail elements. Heat rejection item $1.8 \%$, pump \&aux things $5.5 \%$, fans $9.9 \%$, cooling spaces $32.6 \%$, exterior loads $3.1 \%$, lights $20.9 \%$ and others about $26.2 \%$. All the parameters in the electric other than music and lights comes under HVAC tools. In fuel use entire things comes under hot water making instrument is $100 \%$. No HVAC tools are used with fuel.

* Note: Details shown below are for the Base Run revit work 6-03-2020.0008
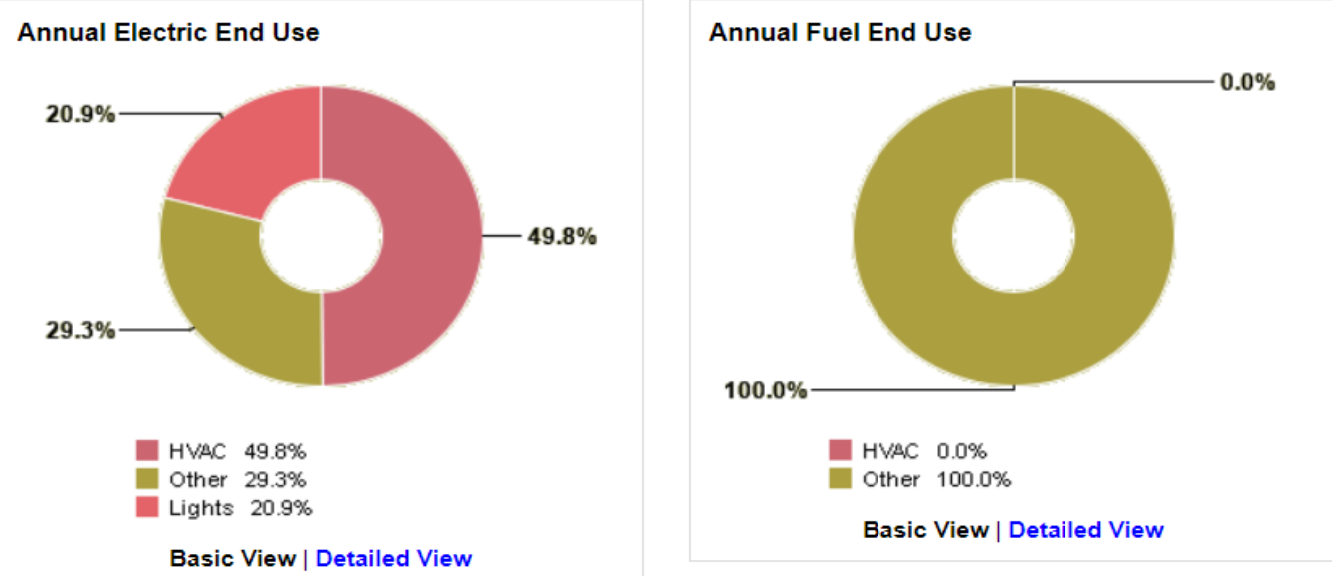

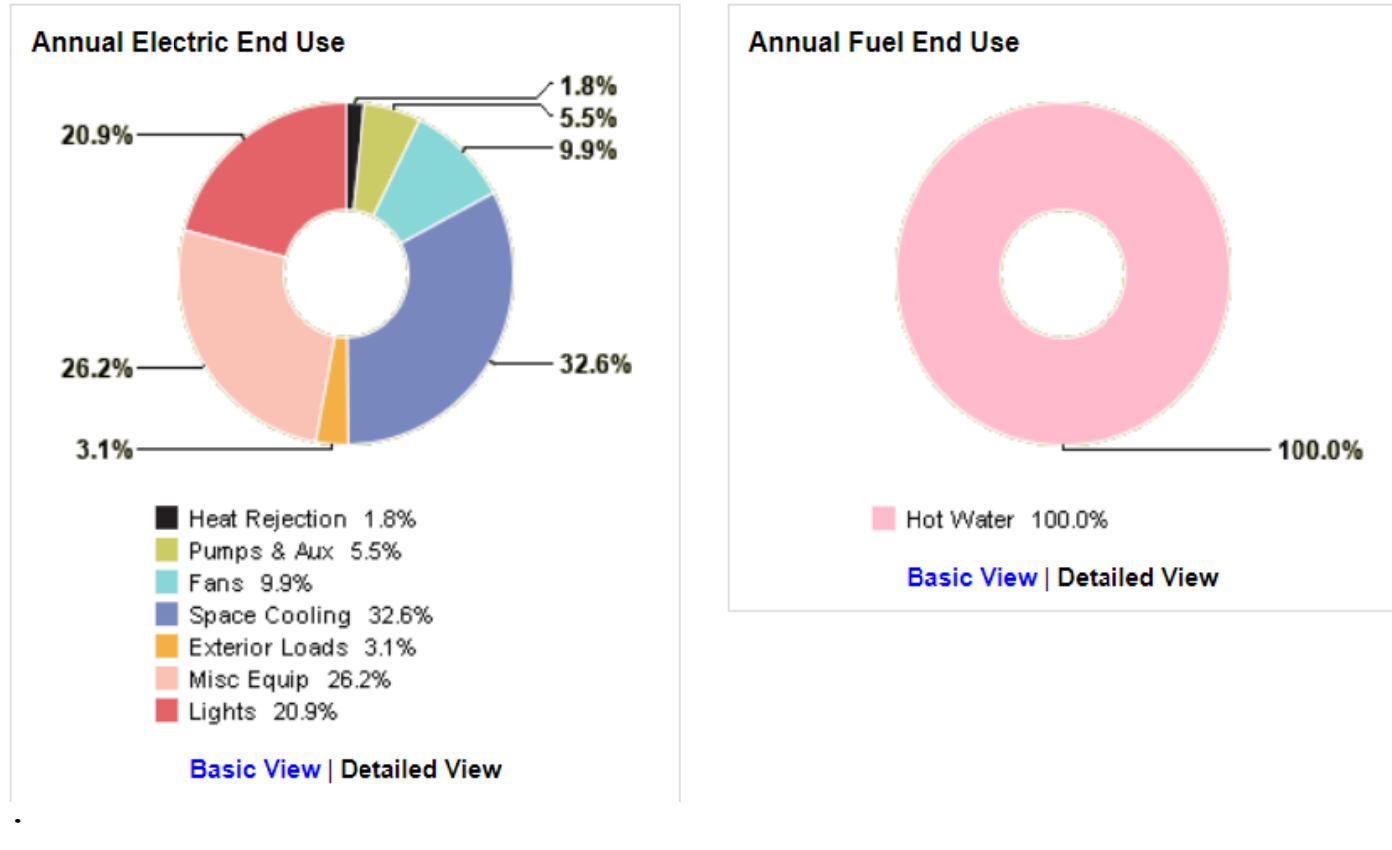

\section{HVAC Result}

The figure is the output generated from the result of the best model selected from the three models. The results presented in this section show the annual cost of the chosen building along with the life cycle cost. The Revit Architecture model is transferred to the Green Building Studio online simulator, the software will consider the prevailing attributes of the location by undertaking all kinds of features related to environment, wind flow etc. the below output shows the result delivered by the software. As a whole, the annual cost of the building is identified as $\$ 11,966$ with life cycle cost as $\$ 162.976$.

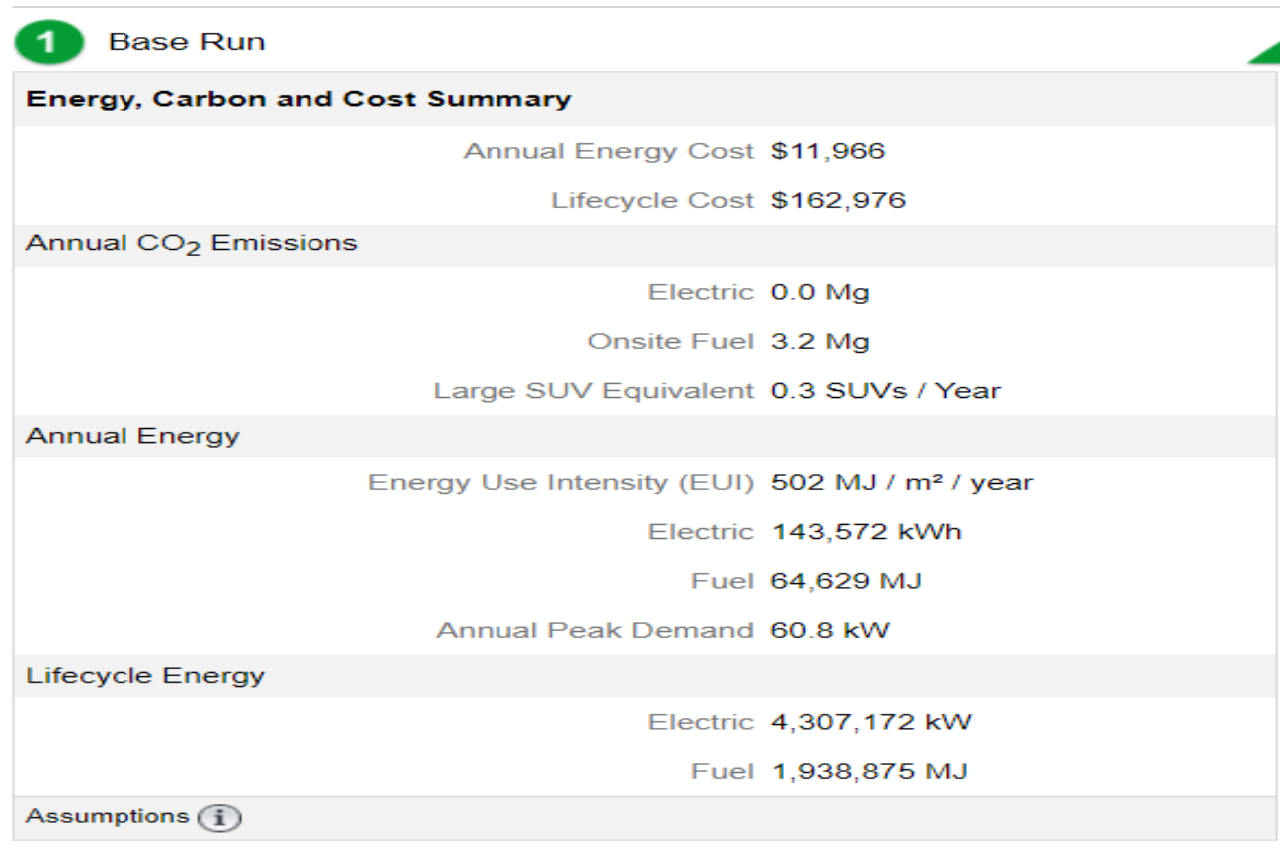




\subsubsection{Ventilation Results}

The below ventilation results show us the need for artificial ventilation throughout the year for the simulated model. The graphs above show the courtyard house's

month-wise results with three types of energies: total energy, electricity requirement, and external sources of energy. The first graph shows the overall requirement of various energy needs as per the chronological order mentioned on the graph's left side. In contrast, external sources' need looks minimal due to the courtyard principles followed by the traditional courtyard buildings. Also, the other graphs show the need and the dependencies of the other types of sources. The green building studio allows analyzing every year and month-wise to get the natural ventilation's consumption and availability to reduce the external usage of sources. It is identified in July that requirement and consumption of energy are recorded as nominal due to building at study area and supporting the environment.

Based on the results delivered by the GBS software, it is evident that HVAC of building will play a key role in energy consumption. Also, if the building has poor design of HVAC, the building may end up with more consumption and mostly end up with burden for client. The below results show the combination of energy consumption during day and night time by means of both electricity and gas. This study is mentioned to be unique, because, the study is offering the Life cycle analysis of the court yard house to have in-depth analysis of the location and the building. 
Chart Sort:

\section{Chronological}

Alphabetical 1 .

Run Total

$\square$ Area Lights

$\square$ Ext Usage

$\square$ Misc Equip

$\square$ Space Cooling

$\square$ Heat Rej

$\square$ Vent Fans

$\square$ Pumps Aux

$\square$ Space Heat

$\square$ Hot Water

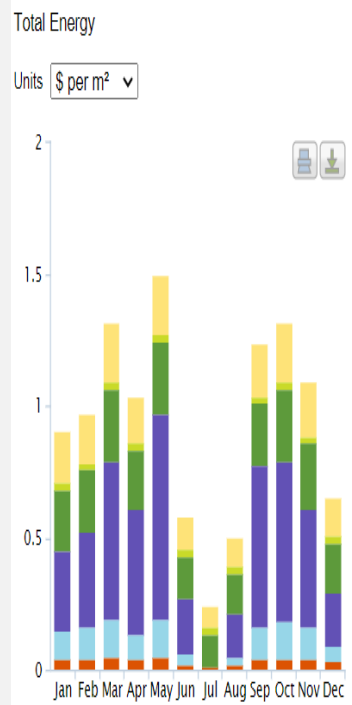

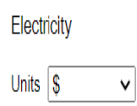

2,000

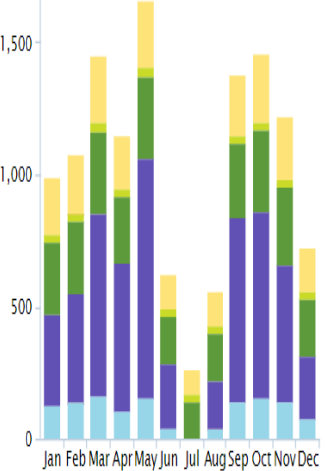

Fuel (Natural Gas)

Units $\$ \quad v$

80

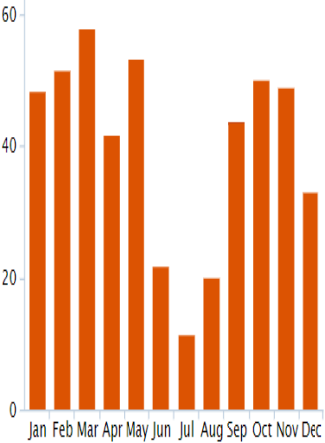

Display Charts For: Dayilighing \& Occupancy Contro__aylighting Controls

0 Cost $O$ Energy

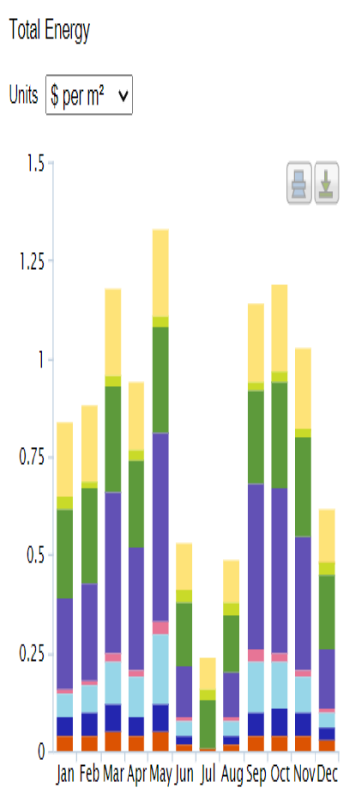

Electirity

Units $\$ \quad v$

2,000

1,500

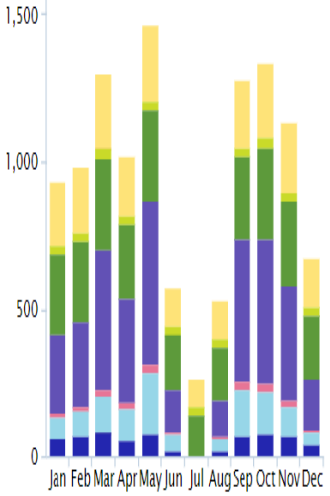

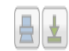

Fuel (Natural Gas)

Units $\$ \quad v$

80

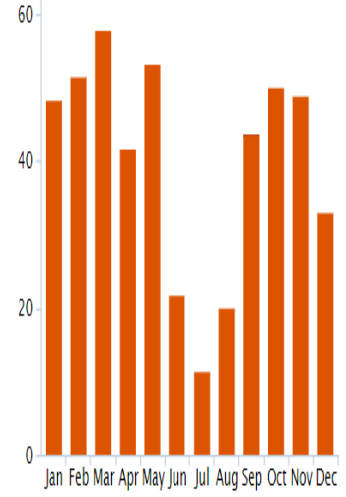




\subsection{Design Solution}

A. In the case, based on the simulation results research Model 2 has higher efficiency than others when compared wind speed and wind whrilpool. Basic wind speed of model 1 is greater than the model 2 but the amount whrilpool is higher in model 1.

B. Research model 1, when the height of the building is constant, the ratio of width to length is increases.Changes have taken place. In the evaluation indicators studied in this article, the wind environment is not as good as the research model 2. During the simulation process, all the three models had given valid results. In addition to the similar studies it was identified that the best model that can suit the climatic conditions, environmental conditions and other features of the study location was given considered as the major choice of the project.

The essence of the literature review, case studies had given greater understanding of the study area. Likewise, the site visit and analysis had help to understand the deep study of the location to provide relevant information to the simulation software. 


\section{Conclusion \& Recommendations}

\subsection{Introduction}

The advantage of constructing Quadrangle Courtyard houses is to reduce the thermal loads imposed on building through internal spaces present in the courtyard. The thermal comfort present in the courtyard house is estimated by wind circulation speed in the building and around the building. Ventilation of a building mostly depends on the open spaces and their quality \& amount of wind speed. Residents of building construct courtyard houses to maintain cool air at night time and sun shade at day time. Courtyard with vegetation will increase the relative humidity of the building. This relative humidity ensures ventilation. Especially on higher floors, relative humidity causes the penetration of ventilation into inner spaces and reduces undesirable sun rays. Wind-driven ventilation is one of the efficient ways to reduce overheating, and provide cooling in dry months, especially in a humid climate. Based on the previous works, there is little attention given to the Wind-driven capacity to increase the natural ventilation capability. Considering the advancement in architectural techniques for ventilation, warming, power, acoustics, lighting, and so forth besides the presentation of new and better material techniques, insightfully, it could be accepted that the utilization of conventional systems, especially in quadrangle courtyard houses. The advancement in architectural technology would enhance the resolution of building and their economic demands coherently and sensibly. Results are presented in a way that adapting the best conditions for the contemporarily-built environment with the climate based on conventional factors to reach sustainable contextual courtyards. It depended on the best model chosen through wind simulation. It may show better results based depend upon the area of area, length to width aspect ratio. 


\subsection{Research Objectives Revisited}

To test the efficiency of a Quadrangle courtyard building after its constructions with improved designs by using a wind environment simulation software Phoenics and Green simulation by using Green Build studio. Phoenics is generally used for C.F.D. (computational Fluid Dynamics) in one dimensional, Two dimensional, and Three Dimensional in both Turbulent and laminar flows. Phoenics is also used for compressible and incompressible flows. In this project, the software is used for the base model and two improved Research models for wind simulation to estimate the speed of wind and age of air at the site. Green build software is used to calculate the ventilation and Daylight sequence of the courtyard. The Green build studio gives the results of energy consumption in terms of annual and life cycle consumption. The first stage of the green simulation to estimate the energy consumption collect the $3 \mathrm{D}$ model of the courtyard building and export as a gbXML file format for further analysis Green build studio (A. S. Shivsharan et al., 2017).

The suggested materials for the study area Materials:Traditional Chinese courtyards are made up of clay, bamboo sticks, wood, and cotton silks, and plastering is made up of clay to protect the wall against rain in monsoon and heat in summer. These materials consume a large amount of energy to fulfilling the green building environment. Normally architects state a 3R (Reduce, Recycle, and Reuse) rule to decrease the non-renewable energy resources consumption. Walls are the main components of a courtyard to sustain against loads, but they are also used as insulating objects in the building environment. Usually they take more amount of cost for their construction, but it can be reduced in a green construction way. They are considered two aspects: green materials for cement reinforcement and recycled construction materials. Concrete is a mix of cementations materials and other composite materials. It is the cheapest hard 
material having several advantages like high plasticity, strong compression stress, and long durability. Concrete will maintain sustainable development. Through green admixtures like grading slag, fly ash, silica fume, and many in cement materials to reduce pollution affected by them. In order to the renovation of traditional courtyards, they are here using reinforcement for increasing the tensile nature of the courtyard building. Nowadays natural plant fibres are used as a replacement for reinforcement. By recycling of traditional building material, the owners can collect the burned items in the process demolition of the building, and they are used for external wall works. The materials like broken bricks for foundation filling and the same way, the builder can use wooden materials for decorative activities.

Understanding of Orientation for the study area: The shape of the courtyard house is square, rectangle, triangular, or circular based on the environmental conditions present in the site. Beijing is in the climatic zone of containing four seasons winter (November to March), summer (June to August), spring (April to May), and autumn (September to October). The geographical position of Beijing located in the northeast of China has the diversity in the climate with four seasons of continental monsoon, widespread winds during summer coming from southeast and northwest in the winter. It is affected by the strong Mongolian high pressure in winter, forming the world's coldest region at the same latitude. While in summer it is affected by the North Pacific subtropical high forming a typical continental monsoon climate $(\mathrm{Hu}$, 2012). In other words, Beijing is in the transition zone between dry and cold airflow and warm and humid airflow. According to the Beijing Statistical Yearbook (2019), the average annual sunshine duration in Beijing from 2007 to 2016 is 2421.1 hours, and the average daily sunshine time in Beijing is 6.6 hours. This means that Beijing can be exposed to sunlight $63 \%$ of the daytime during the years, so it is concluded at the end of the paragraph that the sunshine conditions in Beijing are good. Beijing has four seasons each year, with winter from December to February and summer 
from June to August. The average annual temperature between the years of 2007 to 2016 is $13.5^{\circ} \mathrm{C}$. Beijing's coldest month occurs in January, accompanied by wind, rain, and snow. The average temperature in the month is $-3.1^{\circ} \mathrm{C}$ over an average temperature of $-0.9^{\circ} \mathrm{C}$ in winter.

In contrast, summer temperatures are relatively comfortable, at $26.4^{\circ} \mathrm{C}$. The hottest month in summer is in July when the average temperature is only slightly higher than the summer's average temperature, maintained at about $27.4^{\circ} \mathrm{C}$. Based on the above criteria, in the winter season, the cold waves are travel from northwest to the courtyard building. The degree of enclosure on the northwest direction is high, and that corner becomes the windscreen of the courtyard. The average wind speed in the courtyard is about 0.25 to $0.5 \mathrm{~m} / \mathrm{s}$, conducive to the thermal insulation and energy saving of the courtyard building. For maintaining thermal conditions more appropriately, the opening in the south direction for the improved design is based on phoenics simulation literature Review (Xiaodong Xu et al., 2018). Every window and door is accurately parallel to others to decrease wind on the courtyard and to increase the circulation of air in the interior of the building. Finally, with the help of the above chapters the study proves the parameters such as total adjustment of building dependent on the width to length ratio, spatial layout, and building ecological buffer space are the influential elements.

\subsubsection{Research Objective 1}

Beijing has caused a number of issues regarding the sustainability of contemporary buildings, which in turn negatively affected the living standards and lifestyle of its residents. 
To develop sustainable design strategies for reconstruction and renovation of the contemporary residential buildings in Beijing-

The study had utilized the renovation details and other kinds of back ground data by means of site visit and the software platforms selected for this study had given an opportunity to study and understand the features before construction.

\subsubsection{Research Objective 2}

To investigate the implications of construction and architectural practices adopted in the past on the development and building of traditional courtyard houses in Beijing.

\subsubsection{Research Objective 3}

To examine the impact of quadrangle Courtyard Green Simulation on residential buildings in Beijing.

\subsection{Implication of Research}

Based on the Phoenics simulation on Research models, results are as follows:

The maximum wind speed less than $5 \mathrm{~m} / \mathrm{sec}$ and less number of whirlpool system provides a better living site. Based on the criteria, model 2 is more efficient. For model 2 , the wind speed ranges from 0.46 to $2.78 \mathrm{~m} / \mathrm{s}$, and its maximum wind speeds up to $2.78 \mathrm{~m} / \mathrm{s}$. Its living conditions were comfortable. The effect of wind on the model is not influential, and the age of air present at the model to the region is about 8 to 18 seconds. The wind speed occurs at the northeast corner of the courtyard building. The total number of wind whirlpool occurs at the internal patio is one, and in the overall courtyard is 3 , which is providing better living conditions at 
cha'er hutong, Beijing. Green simulation results of the model as it consumes $143,572 \mathrm{Kwh}$ electricity intensity and fuel intensity of 64,629 MJ. They cost about an annual energy cost of 83059.06 Chinese yuan and lifetime energy cost of 1131265.31 Chinese yuan.

Table 7. Simulation Results of the Model chosen for the study above $1.5 \mathrm{~m}$ pedestrian height.

\begin{tabular}{|c|c|c|c|c|}
\hline Position & Simulation Result & $\begin{array}{c}\text { Base } \\
\text { Model }\end{array}$ & Model 1 & Model 2 \\
\hline \multirow{7}{*}{$\begin{array}{c}\text { Internal } \\
\text { Patio }\end{array}$} & Wind Speed Range & $0-2.63$ & $0.01-3.04$ & $0.46-2.78$ \\
\hline & $\begin{array}{l}\text { Maximum wind speed range } \\
\qquad \mathrm{m} / \mathrm{s}\end{array}$ & $0.48-1.19$ & $1.53-2.28$ & $0.93-1.62$ \\
\hline & $\begin{array}{l}\text { Maximum wind speed range } \\
\qquad \mathrm{m} / \mathrm{s}\end{array}$ & $1.19-2.63$ & $2.28-3.04$ & $1.62-2.78$ \\
\hline & Comfort Evaluation & $\begin{array}{c}\text { Comfortab } \\
\text { le }\end{array}$ & Comfortable & $\begin{array}{c}\text { Comfortab } \\
\text { le }\end{array}$ \\
\hline & Wind Influence & $\begin{array}{c}\text { Does not } \\
\text { effect }\end{array}$ & $\begin{array}{c}\text { Does effect by } \\
\text { whrilpool }\end{array}$ & $\begin{array}{c}\text { Does not } \\
\text { effect }\end{array}$ \\
\hline & Air Age Range /s & $13-21$ & $4.84-9.62$ & $8-18$ \\
\hline & Wind Whrilpool Piece & 0 & 2 & 1 \\
\hline \multirow{3}{*}{$\begin{array}{c}\text { Overall } \\
\text { Courtyard }\end{array}$} & Maximum wind speed & $1.19-2.63$ & $2.28-3.04$ & $1.62-2.78$ \\
\hline & Appearance & $\begin{array}{c}\text { Northeast } \\
\text { Corner }\end{array}$ & $\begin{array}{c}\text { NortheastCorn } \\
\text { er }\end{array}$ & $\begin{array}{c}\text { Northeast } \\
\text { Corner }\end{array}$ \\
\hline & Wind whrilpool piece & 1 & 5 & 3 \\
\hline
\end{tabular}




\subsection{Limitations}

Despite many advantages, these traditional courtyard houses certain limitations like Insects in the surrounding environment can easily enter into the courtyard due to open-top roof, vegetation, and fountain arrangement cause breeding of insects. This type of open-top roof can provide easy access for thieves into the house and cause burglars. The inclined roof causes stagnation of dust. To maintain cleanliness, it has to perform cleaning operations regularly. Based on the economy it is costlier than the normal buildings due to an increase in wall area and space arrangements. It increases insolate family activities in children, which creates a negative impact on them by neighbourhood children. With appropriate design, materials, and construction, courtyards can overcome these limitations. However, it requires special maintenance for cleaning dust in the interior courtyard when they open to the sky.

\subsection{Closing Remark}

The study is to identify the better model that can suit for the current undertaken study. The selected model 2 had performed well apart from the remaining models. Software like Phoenics and Green building studios were deployed to identify the feasible model and overall energy consumption for a year and life cycle. For this study, the software track the right model that can suit the study location. People need green gardens. They want to be in nature and be away from the urban 'hustle and bustle.' The city of Beijing is full of parks; at least one park is located in every urban center. People in the city want to avoid their busy working to enjoy peaceful locations for refreshment (Donia Zhang et al., 2006). To increase vegetation area within the house to maintain a peaceful environment courtyard is coming into existence. Quadrangle Courtyards are providing multiple advantages such as visual privacy, climatic benefits, vegetation, 
acoustic environment for building, etc., increases the living conditions.

Standardization of courtyard design, material, and construction reduce cost when compared to urban complex block and increases aviation around the building, ventilation. According to the poet T.S Eliot (1968) is concluded as follows "Time Present and Time Past are both perhaps present in time future and time future contained in time past”. 


\section{References}

Abutabenjeh, S., \&Jaradat, R. (2018). Clarification of research design, research methods, and research methodology. Teaching Public Administration, 36(3), 237-258. doi:10.1177/0144739418775787

Al-Masri, N., \& Abu-Hijleh, B. (2012). Courtyard housing in midrise buildings: An environmental assessment in hot-arid climate. Renewable and Sustainable Energy Reviews, 16(4), 1892-1898. doi:10.1016/j.rser.2012.01.008

Aldawoud, A. (2008). Thermal performance of courtyard buildings. Energy and Buildings,40(5), 906-910. doi:10.1016/j.enbuild.2007.07.007

Alexander, A., Hirako, Y., Dorje, L., \& De Azevedo, P. (2003). Beijing Historic City Study. Retrieved November 04, 2020, from http://www.achr.net/UAC\%20Web\%20DLs/ Beijing02a.doc.

Bai, H. (2007). Living in the old Beijing (《老北京的居住》, Chinese edition). Beijing: Yanshan Publishing House

Berardi, U., \& Wang, T. (2014). Daylighting in an atrium-type high performance house. Building and Environment,76, 92-104. doi:10.1016/j.buildenv.2014.02.008

Chiang, Wei-Hwa, \& Anh, Nguyen Duc. (2012). Natural Ventilation Inside Courtyard-Apartment Building in Taiwan. D'Agostino, Delia, \&Congedo, Paolo 
Maria. (2014). CFD modeling and moisture dynamics implications of ventilation scenarios in historical buildings. Building and Environment, 79(0), 181-193. doi: http://dx.doi.org/10.1016/j.buildenv.2014.05.007

Cannistraro, G., Cannistraro, M., \& Restivo, R. (2015). Smart Control of Air Climatization System in Function on the Values of Mean Local Radiant Temperature. Smart Science,3(3), 157-163. doi:10.1080/23080477.2015.11665651

Cao, B., Luo, M., Li, M., \& Zhu, Y. (2016). Too cold or too warm? A winter thermal comfort study in different climate zones in China. Energy and Buildings,133, 469-477. doi:10.1016/j.enbuild.2016.09.050

Costa, A. A., Lopes, P. M., Antunes, A., Cabral, I., Grilo, A., \& Rodrigues, F. M. (2015). 3I Buildings: Intelligent, Interactive and Immersive Buildings. Procedia Engineering,123, 7-14. doi:10.1016/j.proeng.2015.10.051

Delgarm, N., Sajadi, B., Kowsary, F., \&Delgarm, S. (2016). Multi-objective optimization of the building energy performance: A simulation-based approach by means of particle swarm optimization (PSO). Applied Energy,170, 293-303. doi:10.1016/j.apenergy.2016.02.141

D'agostino, D., \&Congedo, P. M. (2014). CFD modeling and moisture dynamics implications of ventilation scenarios in historical buildings. Building and Environment,79, 181-193. doi:10.1016/j.buildenv.2014.05.007

Ekici, B., Cubukcuoglu, C., Turrin, M., \&Sariyildiz, I. S. (2019). Performative 
computational architecture using swarm and evolutionary optimisation: A review. Building and Environment,147, 356-371. doi:10.1016/j.buildenv.2018.10.02

Ghaffarianhoseini, A., Berardi, U., \&Ghaffarianhoseini, A. (2015). Thermal performance characteristics of unshaded courtyards in hot and humid climates. Building and Environment,87, 154-168. doi:10.1016/j.buildenv.2015.02.001

Gold, J. R. (1998). Creating the Charter of Athens: CIAM and the functional city, 1933-43. Town Planning Review,69(3), 225. doi:10.3828/tpr.69.3.2357285302g10321

Gou, S., Nik, V. M., Scartezzini, J., Zhao, Q., \& Li, Z. (2018). Passive design optimization of newly-built residential buildings in Shanghai for improving indoor thermal comfort while reducing building energy demand. Energy and Buildings,169, 484-506. doi:10.1016/j.enbuild.2017.09.095

Han, B., Ouyang, Z., Liu, H., Cui, Z., Lu, Z., \& Crittenden, J. (2016). Courtyard integrated ecological system: An ecological engineering practice in China and its economic-environmental benefit. Journal of Cleaner Production, 133, 1363-1370. doi:10.1016/j.jclepro.2016.06.061

Hu, M., Bergsdal, H., Voet, E. V., Huppes, G., \& Müller, D. B. (2010). Dynamics of urban and rural housing stocks in China. Building Research \& Information,38(3), 301-317. doi:10.1080/09613211003729988

Haves, P., Hafemeister, D., Kammen, D., Levi, B. G., \& Schwartz, P. (2011). Energy Simulation Tools for Buildings: An Overview. Conference Proceedings,1401, 311-327. doi:10.1063/1.3653860 
Jang, N., \& Ham, S. (2017). A study on courtyard apartment types in South Korea from the 1960s to 1970s. Frontiers of Architectural Research,6(2), 149-156. doi:10.1016/j.foar.2017.03.004

Knapp, R. G. (2000). China's old dwellings. Honolulu: University of Hawai‘i Press.

Khan, N., Su, Y., \&Riffat, S. B. (2008). A review on wind driven ventilation techniques. Energy and Buildings,40(8), 1586-1604.

doi:10.1016/j.enbuild.2008.02.015

Korkmaz, S., Messner, J. I., Riley, D. R., \&Magent, C. (2010). High-Performance Green Building Design Process Modeling and Integrated Use of Visualization Tools. Journal of Architectural Engineering,16(1), 37-45.

doi:10.1061/(asce)1076-0431(2010)16:1(37)

Kubota, T., Toe, D. H., \&Ossen, D. R. (2014). Field Investigation of Indoor Thermal Environments in Traditional Chinese Shophouses with Courtyards in Malacca. Journal of Asian Architecture and Building Engineering,13(1), 247-254. doi:10.3130/jaabe.13.247

Lakshman, M., Sinha, L., Biswas, M., Charles, M., \& Arora, N. K. (2000). Quantitative Vs qualitative research methods. The Indian Journal of Pediatrics,67(5), 369-377. doi:10.1007/bf02820690

Lee, S. (2016). Capitalistic Transition of Housing System Under Socialist Market Economy: Characteristics of Chinese Housing Regime After Reform and Opening-up. 
Journal of the Economic Geographical Society of Korea,19(4), 743-763.

doi:10.23841/egsk.2016.19.4.743

Wang, L. (2014). Rehabilitating the Old City of Beijing: A Project in the Ju'er Hutong Neighbourhood. Vancouver: UBC Press.

Lama, U. T. (2018). Understanding Social Media : Functionality and Differentiating Social Media and Social Networking Sites. International Journal for Research in Engineering Application \& Management,24(5), 126-133.

doi:10.18231/2454-9150.2018.0576

Ministry of Construction of the People's Republic of China. (Ed.). (1993). Standards on the Climatic Zoning of Buildings (GB50178-93). Beijing, China: China Planning Press.

Ma, B. (1999). The architecture of the quadrangle in Beijing (《北京四合院建筑》, Chinese edition). China: Tianjin University Press.

Moosavi, L., Mahyuddin, N., \&Ghafar, N. A. (2015). A comparison between atrium and courtyard cooling efficiency in hot tropical climate, implementing different passive cooling strategies. Journal of Renewable and Sustainable Energy,7(4), 043108. doi:10.1063/1.4926760

Martinelli, L., \&Matzarakis, A. (2017). Influence of height/width proportions on the thermal comfort of courtyard typology for Italian climate zones. Sustainable Cities and Society,29, 97-106. doi:10.1016/j.scs.2016.12.004 
Rajapaksha, I., Nagai, H., \&Okumiya, M. (2003). A ventilated courtyard as a passive cooling strategy in the warm humid tropics. Renewable Energy,28(11), 1755-1778. doi:10.1016/s0960-1481(03)00012-0

Simiu, E., \& Scanlan, R. H. (1986). Wind effects on structures: An introduction to wind engineering. New York: Wiley.

Stupar, A. (2015). Cold War vs. architectural exchange: Belgrade beyond the confines? Urban History,42(4), 622-645. doi:10.1017/s0963926815000528

Sun, P. (1981). Review: Courtyard Houses in China: Tradition and Present by Werner Blaser. Journal of the Society of Architectural Historians,40(2), 145-145. doi: $10.2307 / 989730$

Soflaei, F., Shokouhian, M., \&Shemirani, S. M. (2016). Investigation of Iranian traditional courtyard as passive cooling strategy (a field study on BS climate). International Journal of Sustainable Built Environment,5(1), 99-113. doi:10.1016/j.ijsbe.2015.12.001

Taleghani, M., Kleerekoper, L., Tenpierik, M., \&Dobbelsteen, A. V. (2015). Outdoor thermal comfort within five different urban forms in the Netherlands. Building and Environment,83, 65-78. doi:10.1016/j.buildenv.2014.03.014

Taleghani, M., Tenpierik, M., \&Dobbelsteen, A. V. (2012). Environmental Impact Of Courtyards-A Review And Comparison Of Residential Courtyard Buildings In Different Climates. Journal of Green Building,7(2), 113-136. doi:10.3992/jgb.7.2.113 
Veerendra, G., Prasad, C. D., \&Baburao, A. G. (2014). Procurement-Principle

Towards Effective Management Of Construction Projects. International Journal of Research in Engineering and Technology,03(06), 624-629.

doi:10.15623/ijret.2014.0306116

Wang, Q. (1999). Beijing Siheyuan (《北京四合院》, Chinese edition). Beijing: China Bookstore

Wang, X. (2013). Interpreting Chinese Traditional Folk Houses from the Angle of Chinese Traditional CultureXis. Applied Mechanics and Materials,357-360, 108-111. doi:10.4028/www.scientific.net/amm.351-352

Waibel, C., Wortmann, T., Evins, R., \&Carmeliet, J. (2019). Building energy optimization: An extensive benchmark of global search algorithms. Energy and Buildings,187, 218-240. doi:10.1016/j.enbuild.2019.01.048

Xiong, W. (2016). Translated and annotated version of the 2015-2020 National Mental Health Work Plan of the People's Republic of China (M. R. Phillips, Trans.). Shanghai Archives of Psychiatry, 28(1), 4-17. doi:10.11919/j.issn.1002-0829.216012.

Xu, X., Luo, F., Wang, W., Hong, T., \& Fu, X. (2018). Performance-Based Evaluation of Courtyard Design in China's Cold-Winter Hot-Summer Climate Regions. Sustainability,10(11), 3950. doi:10.3390/su10113950

Yang, Q. (2014). Space Modernization and Social Interaction: A Comparative Study 
of Living Space in Beijing. Berlin: Springer.

Yang, X., Li, Y., \& Yang, L. (2012). Predicting and understanding temporal 3D exterior surface temperature distribution in an ideal courtyard. Building and Environment,57, 38-48. doi:10.1016/j.buildenv.2012.03.022

Zhang, D. (2006). New courtyard houses of Beijing: Direction of future housing development. URBAN DESIGN International,11(3-4), 133-150. doi:10.1057/palgrave.udi.9000173

Zhang, D. (2011). Courtyard houses of Beijing: Past, present, and future. Saarbrücken: VDM Verlag Dr Müller.

Zhang, D. (2013). Courtyard housing and cultural sustainability: Theory, practice, and product. Farnham: Ashgate Publishing.

Zhang, D. (2015). Traditional Dwellings and Settlements Review. Courtyard Houses of Beijing: Lessons from the Renewal,27, no.1, 69-82. https://www.jstor.org/stable/24720001

Zhang, Y., Kang, J., \&Jin, H. (2018). A Review of Green Building Development in China from the Perspective of Energy Saving. Energies,11(2), 334.

doi:10.3390/en11020334 